ISNARD DA SILVA CARVALHO

\title{
Resposta a placebo em ensaios clínicos com antidepressivos: análise de características de personalidade e variáveis genéticas
}

Dissertação apresentada ao Departamento de Farmacologia do Instituto de Ciências Biomédicas da Universidade de São Paulo, para a obtenção do título de Mestre em Ciências na área de Farmacologia. 
ISNARD DA SILVA CARVALHO

Resposta a placebo em ensaios clínicos com antidepressivos: análise de características de personalidade e variáveis genéticas

Dissertação apresentada ao Departamento de Farmacologia do Instituto de Ciências Biomédicas da Universidade de São Paulo, para a obtenção do título de Mestre em Ciências na área de Farmacologia.

Orientadora:

Prof. Dra. Clarice Gorenstein

Colaboradora: Dra. Daniela Sabbatini da Silva Lobo 


\section{DEDICATÓRIA}

Aos grandes incentivadores $e$ responsáveis pela minha formação: Meus pais Lafayette e lolanda e À minha filha: Marina Calegari Carvalho 


\section{AGRADECIMENTOS}

À Profa. Dra. Clarice Gorenstein, pela oportunidade, paciência, dedicação e por todos os ensinamentos.

Á Profa Dra. Daniela Lobo, por toda orientação na área da genética e pela grande contribuição ao trabalho.

À meus pais, Lafayette e lolanda pelo grande apoio que me deram durante toda minha jornada e principalmente nos momentos de maiores dificuldades.

Á Claudia C.R. Vasconcelllos, pela amizade, dedicação e ajuda na elaboração da aula de qualificação e na confecção dessa dissertação.

Ao irmão e Dr. Eduardo F Carvalho Netto, pelo apoio e orientação quando necessário.

À meu irmão Ivan S Carvalho, por me acolher em sua residência quando eu precisei e pela amizade

Á Maria Venier Romano (Vó Pina) e Leonilda Romana (Tia Nida), pelos incansáveis orações e novenas.

Às amigas do laboratório Claudia Valéria Garcia, Eliene Santana e Mônica Estavarengo, pela amizade, companheirismo e apoio.

Ás Dra Elaine Henna e Mônica L. Zilberman, pela amizade, sugestões e apoio na condução desse trabalho.

À Mercia Cristina Calegari, pela paciência, apoio e incentivo e por sua dedicação integral a nossa filha.

À todos os meus irmãos, Ivan, Eduardo, José Ricardo e Juliana pelo apoio e incentivo.

Aos meus amigos Julio e Patrícia Munerato, por me acolherem em sua casa durante três meses e, pela amizade e apoio de sempre. 


\section{RESUMO}

Carvalho IS. Resposta a placebo em ensaios clínicos com antidepressivos: análise de características de personalidade e variáveis genéticas [dissertação]. São Paulo: Instituto de Ciências Biomédicas da Universidade de São Paulo; 2008.

O efeito placebo caracteriza-se pela redução de um sintoma ou melhora de um quadro clínico que se obtém após a administração de uma substância farmacologicamente inerte (placebo) ou um procedimento sabidamente ineficaz. $O$ efeito placebo tem sido observado em diferentes doenças e sintomas e a magnitude de resposta varia entre $30 \%$ a $70 \%$. Alguns fatores que estão associados ao efeito placebo são conhecidos e diversas teorias tentam elucidar os mecanismos psicobiológicos envolvidos na resposta a placebo. No entanto, o entendimento ainda é limitado. Objetivos: a) Verificar se há característica de personalidades associadas à resposta a placebo em estudos com antidepressivos; b) Verificar se há associação de polimorfismos em genes do sistema serotonérgico com resposta a placebo. Métodos: Foram incluídos no estudo pacientes que participaram de ensaios clínicos com antidepressivos e placebo conduzidos no Instituto de Psiquiatria do Hospital de Clínicas da Faculdade de Medicina da USP (IPQ-HCFMUSP), entre 2000 e 2005. Os sujeitos $(n=57)$ [pacientes deprimidos $(n=14)$, pacientes fóbicos $(n=22)$ e voluntários saudáveis $(n=21)]$ foram considerados respondedores a placebo, de acordo com os critérios estabelecidos pelo estudo de origem. Para a análise das variáveis de personalidade os sujeitos responderam o Inventário de Temperamento e Caráter (ITC) e para a análise das variáveis genéticas foram escolhidos três genes polimórficos do sistema serotonérgico: do transportador de serotonina (SLC6A4), do receptor de serotonina subtipo $2 \mathrm{~A}$ (HTR2A) e do receptor de serotonina subtipo $1 \mathrm{~B}$ (HTR1B). Análise estatística: foi utilizado o modelo de análise discriminante para avaliar o comportamento das variáveis [idade, escolaridade, gênero e diagnóstico] e uma regressão logística para verificar quais destas variáveis explicavam as diferenças observadas entre os respondedores e não respondedores, bem como seu grau de importância. Resultados: Não houve diferenças estatisticamente significativas entre os respondedores e não respondedores a placebo, em relação à idade, escolaridade e gênero. Os respondedores a placebo apresentaram escores significativamente maiores nos fatores de personalidade busca de novidade e autotranscendência quando comparados aos não respondedores. Os resultados da 
análise genética mostraram uma sugestiva associação entre dois genes polimórficos [o 5HTTLPR (SLC6A4) e o gene 5HTR1B (G861C)] e a resposta a placebo. Conclusões: Os resultados sugerem que a resposta a placebo é influenciada por características de personalidade em sujeitos sadios e pacientes com diagnóstico de fobia social e depressão e por polimorfismos genéticos em sujeitos sadios.

Palavras-chaves: Efeito placebo; Resposta placebo; Características de personalidade; Variáveis genéticas; Polimorfismos; ITC 


\begin{abstract}
Carvalho IS. Placebo response in clinical trial with antidepressants: personality characteristics and genetics variables [Dissertation]. São Paulo: Instituto de Ciências Biomédicas da Universidade de São Paulo; 2008.
\end{abstract}

The placebo effect is characterized by symptom reduction or the improvement of a clinical picture after the administration of a pharmacological inert substance (placebo) to be ineffective or a procedure already known to be ineffective. The placebo effect has been observed in different illnesses and symptoms and the magnitude of this response varies from $30 \%$ to $70 \%$. Some factors associated with the placebo effect are known and various theories aid to elucidate the psychobiological mechanisms involved in the placebo response; however, the knowledge is still limited. Objectives: a) To verify if personality characteristics are associated with placebo response in studies with antidepressants, b) To verify if polymorphisms in serotonergic system genes are associated with placebo response. Methods: Patients that participates in clinical trials of antidepressants and placebo realized at the Instituto de Psiquiatria do Hospital de Clínicas da Faculdade de Medicina da USP (IPQ-HCFMUSP), among 2000 to 2005 were included. Subjects $(n=57)$ [depressed patients $(n=14)$, phobia social patients $(n=22)$ and healthy volunteers $(n=21)$ ] were classified as placebo respondents following criteria established criteria by the origin study. For the personality analysis, subjects answered the Inventory of Temperament and Character (ITC) and for the genetic analysis, were chosen three polymorphic genes: the serotonin transporter (SLC6A4), the serotonin receptor subtype 2A (HTR2A) and the serotonin receptor subtype 1B (HTR1B). Analysis statistics: A discriminate analysis model was used to evaluate the variables behavior [age, education, gender and diagnostic] and a logistic regression to verify, which of these variables explained the differences observed between placebo respondents and no respondents, as well as its degree of importance. Results: There were no significant statistical differences between placebo respondents and non respondents regarding age, education, and gender Placebo respondents presented a significantly higher score's for personality factors novelty seeking and self-transcendence in comparison to non respondents. The results of the genetic analysis suggest an association between two polymorphic genes [the 5HTTLPR (SLC6A4) gene and 5HTR1B (G861C)] and placebo response. Conclusions: The results suggest that placebo response in healthy volunteers and 
depressed and phobia social patients is influenced by personality characteristics and by genetic polymorphisms in healthy subjects.

Keywords: Placebo effect; Placebo response, Personality characteristics; Genetics variables; ITC. 


\section{LISTA DE TABELAS}

Tabela 1- Número e percentual de respondedores e não respondedores a placebo na amostra total e sub-grupos.

Tabela 2- Características sócio-demográficas dos respondedores e não respondedores a placebo na amostra total $(n=57)$.

Tabela 3- Escores médios no Inventário de Temperamento e Caráter (ITC) dos sujeitos normais e pacientes fóbicos e deprimidos

Tabela 4- Escores médios no Inventário de Temperamento e Caráter dos respondedores $(n=6)$ e não respondedores $(n=15)$ a placebo no grupo de sujeitos normais

Tabela 5- Escores médios no Inventário de Temperamento e Caráter dos respondedores $(n=6)$ e não respondedores $(n=16)$ a placebo do grupo de pacientes com fobia social.

Tabela 6- Escores médios no Inventário de Temperamento e Caráter dos respondedores $(n=4)$ e não respondedores $(n=10)$ a placebo do grupo de pacientes com depressão

Tabela 7- Escores médios no Inventário de Temperamento e Caráter dos respondedores $(n=16)$ e não respondedores $(n=41)$ a placebo comparando-se todos os sujeitos do estudo

Tabela 8- Resultados significativos da regressão multivariada considerando as variáveis idade, gênero, escolaridade e diagnóstico dos fatores de personalidade da amostra total com todos os sujeitos incluídos (Sujeitos normais, pacientes deprimidos e pacientes fóbicos) $(n=57)$

Tabela 9- Comparação das características sócio-demográficas entre os respondedores a placebo e os não respondedores na amostra de sujeitos normais $(n=19)$.

Tabela 10- Análise de associação do polimorfismo 5HTTLPR em 6 sujeitos respondedores e 13 não respondedores a placebo

Tabela 11- Análise de associação do polimorfismo 5HT1B (G861C) em 6 sujeitos respondedores e 13 sujeitos não respondedores a placebo.

Tabela 12- Análise de associação do polimorfismo 5HT2A (T102C) em 6 sujeitos respondedores e 13 sujeitos não respondedores a placebo. 


\section{LISTA DE FIGURAS}

Figura 1- Escores médios dos fatores de personalidade no Inventário de Temperamento e Caráter (ITC) dos diferentes grupos de sujeitos (normais, fóbicos e deprimidos).

Figura 2- Escores médios no Inventário de Temperamento e Caráter dos respondedores $(n=16)$ e não respondedores $(n=41)$ a placebo agrupando-se todos os sujeitos do sujeito

Figura 3- Figura 3 - Análise da distribuição dos genótipos L/L, L/S e S/S do 5HTTLPR (SLC6A4) entre os respondedores e não respondedores a placebo

Figura 4- Análise da distribuição dos genótipos G/G, G/C e C/C do gene do Receptor de Serotonina Subtipo 1B entre os respondedores e não respondedores a placebo.

Figura 5- Análise da distribuição dos genótipos T/T, T/C e C/C do gene HTR2A (T102C) entre os respondedores $e$ não respondedores a placebo.. 
SUMÁRIO

1 INTRODUÇÃO........................................................................... 13

1.1 Histórico.................................................................................................. 14

1.2 Magnitude do efeito placebo................................................................. 15

1.3 Variáveis que interferem da resposta a placebo.................................... 16

1.4 Hipóteses do mecanismo do efeito placebo........................................ 17

1.4.1 Hipótese do condicionamento clássico............................................ 17

1.4.2 Hipótese da expectativa.................................................................... 18

1.4.3 Hipótese da perspectiva motivacional.............................................. 19

1.5 Efeito nocebo........................................................................................ 19

1.6 Estudos de neuroimagem................................................................... 20

1.7 Variáveis genéticas.................................................................................. 21

1.8 Variáveis de personalidade..................................................................... 21

1.9 Variáveis genéticas e características de personalidade........................ 22

2 OBJETIVOS............................................................................................ 24

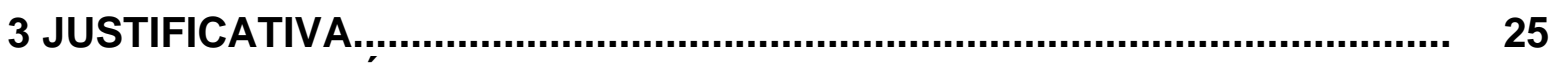

4 MATERIAIS E MÉTODOS........................................................................ 26

4.1 Sujeitos.................................................................................................... 26

4.2 Procedimentos de seleção da amostra................................................ 26

4.2.1 Pacientes com diagnóstico de depressão.......................................... 26

4.2.2 Pacientes com diagnóstico de fobia social........................................ 27

4.2.3 Sujeitos sem diagnóstico psiquiátrico................................................ 28

4.3 Determinação dos critérios para os respondedores................................ 28

4.4 INSTRUMENTOS.................................................................................... 29

4.4.1 Inventário de Temperamento e Caráter (ITC) ................................... 29

4.4.2 Determinação de Marcadores Genéticos............................................ 30

4.4.2.1 Genotipagem..................................................................................... 31

4.4.2.2 Gene do Transportador de Serotonina (SLC6A4)............................ 31

4.4.2.3 Gene do Receptor de Serotonina Subtipo 1B (5HT1B)................... 32

4.4.2.4 Gene do Receptor de Serotonina subtipo 2A (HTR2A)................... 33

4.5 ANÁLISES DOS DADOS...................................................................... 34

4.5.1 Variáveis de personalidade............................................................. 34

4.5.2 Variáveis genéticas.......................................................................... 34

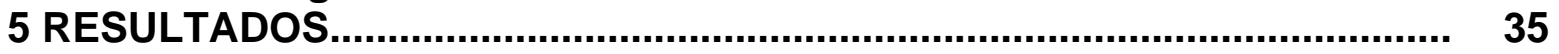

5.1 Comparação das características sócio-demográficas entre os respondedores e não respondedores a placebo........................................ 35

5.2 Variáveis de Personalidade................................................................ 36

5.3 Variáveis genéticas............................................................................ 45

6 DISCUSSÃO.............................................................................................. $\quad 52$

6.1 Amostra.................................................................................................. 52

6.2 Características de Personalidade de sujeitos normais e pacientes psiquiátricos................................................................................................. 52

6.3 Características de personalidade e resposta a placebo......................... 53

6.4 Associação de resposta placebo a polimorfismos de genes do sistema serotonérgicos.............................................................................. 56 
6.5 Limitações do estudo e considerações finais......................................... 58

7 CONCLUSÕES.......................................................................................... 59

REFERÊNCIAS BIBLIOGRÁFICAS....................................................... 60 


\section{INTRODUÇÃO}

O significado da palavra placebo e seu efeito vêm passando por mudanças conceituais desde o início da prática da medicina (Edvin et al., 2007; Grant et al., 2005). Alguns fatores que estão associados ao efeito placebo são conhecidos e diversas teorias tentam elucidar seus mecanismos subjacentes. Pesquisadores buscam entendê-lo por meio de estudos de neuroimagem (Mayberg et al., 2002; Benedetti et al., 2005; Benedetti, 2008; De la fuente-Fernandez et al., 2002; Petrovic et al., 2002) e outros observam a influência de características individuais na resposta a placebo, como por exemplo, variáveis de personalidade (Natrielli, 2002; Hutchison et al., 1999; Raby et al., 2005) e variáveis genéticas (Sakul, 2004; Durham et al., 2003). Mas, em geral, esse fenômeno comum na prática médica e em pesquisa clímca não é bem compreendido (Koshi et al., 2007; Benedetti et al., 2003).

O efeito placebo caracteriza-se pela redução de um sintoma ou melhora de um quadro clínico que se obtém após a administração de uma substância farmacologicamente inerte (placebo) ou de um procedimento sabidamente ineficaz para a situação.

Moerman et al. $(2002,2006)$ acreditam que o termo não é apropriado para se referir a resposta ou ao efeito de um tratamento inerte e sugerem a mudança na denominação para "meaning response" o efeito psicológico ou fisiológico do significado na origem ou tratamento da doença.

Nos últimos cinqüenta anos, o efeito placebo tem assumido um papel fundamental nas pesquisas com fármacos, visto o grande número de publicações disponíveis no PUBMED envolvendo o termo placebo (Macedo e Farre, 2003). Os resultados encontrados nesses estudos sugerem que 0 efeito placebo é parcialmente responsável pelos benefícios obtidos nos tratamentos em todas as especialidades médicas (Geers et al., 2006). 


\subsection{Histórico}

O efeito placebo sempre esteve presente na história médica e atravessou todas as principais civilizações, crenças e avanços tecnológicos (Macedo et al., 2003). A denominação placebo tem origem do latim e foi traduzida para a língua inglesa como "I shall please", "agradarei" em português. Existe registro de que a palavra placebo foi utilizada pela primeira vez no século XIV, pelos acompanhantes contratados para enterros que iniciavam suas lamentações com a frase "Placebo Domino in regione vivorum", traduzido do latim como sendo "Agradarei ao Senhor na terra dos vivos" (Thompson, 2005). Na mesma época, Geoffrey Chaucer (escritor, filósofo e diplomata inglês) descreve em suas histórias um personagem de nome Placebo, que se portava como um homem mal, mentiroso e falso (Craen et al., 1999).

Nas sociedades primitivas, as doenças mentais e grande parte das físicas eram atribuídas a forças sobrenaturais ou maus espíritos. Para explicar esses fenômenos, essas sociedades criaram personagens, conhecidos como "Shaman", "Medicine men" e outras denominações, dependendo da tribo ou cultura (Thompson, 2005; Carvalho, 2004). Todos eram curandeiros que utilizavam cerimônias e rituais para acalmar os espíritos. A "medicina" praticada pelos curandeiros era baseada na crença do paciente e do curandeiro de que o tratamento faria algum bem (Thompson, 2005).

Paracelso, médico suíço que revolucionou a medicina com o uso da homeopatia e de tratamentos químicos, escolhia seus remédios de acordo com as características físico-químicas do produto, mas também pela sua cor e a forma (Macedo et al., 2003)

Em 1747, James Lind realizou o primeiro ensaio clínico registrado na história da medicina, em que testou várias terapias em marinheiros com escorbuto. Nesse período é que o termo placebo passou a ser utilizado no contexto médico, sendo definido em 1811 pelo dicionário Médico Hooper's como o nome dado para qualquer medicamento prescrito mais para satisfazer e agradar o paciente do que para tratar a doença (Craen et al., 1999; Macedo et al., 2003).

Anton et al. (1999) relata que em 1801, John Haygarth, um importante médico britânico, conhecido por desenvolver novos métodos para prevenir a febre em indivíduos com varíola, pode ter realizado o primeiro estudo "placebo" controle. 
Nesse estudo, Haygarth simulou com uma vareta de madeira ("tractors" fictício), um "tractors" patenteado, que era uma vareta metálica utilizada para curar uma variedade de doenças através da força eletrostática. Meio século depois, Austin Flint concluiu que a terapia placebo com tintura de quássia bastante diluída, conhecida como "Placeboic remedy for reumathism", mudava o curso natural do reumatismo, porém não utilizou um grupo controle de pacientes sem nenhum tratamento.

No inicio do século XX, Adolfo Bingel realizou um estudo para avaliar o efeito da antitoxina sérica diftérica nos casos de difteria e comparou com placebo. $\mathrm{Na}$ década de 1930, vários estudos importantes foram publicados sobre a introdução de placebo nas pesquisas clínicas.

\subsection{Magnitude do efeito placebo}

Beecher (1955) publicou um trabalho clássico intitulado "The powerful placebo", no qual quantificou o efeito placebo através da análise de diversos trabalhos publicados e encontrou que em média 35\% dos sujeitos tiveram melhora satisfatória com o uso de placebo em diversas doenças ou sintomas.

Realizando uma busca de trabalhos recentes, publicados no período de 2000 a 2006, pode-se observar diversos estudos descrevendo a magnitude do efeito placebo em diferentes situações e doenças, como por exemplo, 39\% em Doença de Parkinson (De la Fuente Fernandez et al., 2003), 35\% em dispepsia (Talley et al., 2005), 20 a 40\% em insônia (Perlis et al., 2005), 85\% em indivíduos com tosse (Eccles, 2002), 33\% em depressão (Moreno et al., 2005), 23,5\% em fobia social 23,5\% (Oosterbaan et al., 2001), 27\% em esquizofrenia (Welge et al., 2002), 22 a 39\% em analgesia (Macedo et al., 2006).

Em todos esses estudos, a resposta a placebo foi bastante expressiva e em alguns casos, como no de antitussígenos, colocou-se em dúvida a eficácia da maioria dos medicamentos disponíveis (Eccles, 2005). Nos transtornos mentais a resposta a placebo é verificada em até $70 \%$ dos casos e, por isso, o estudo placebocontrole é considerado essencial para determinar a eficácia de medicamentos em psiquiatria (Versiani, 2000). 


\subsection{Variáveis que interferem da resposta a placebo}

A forma farmacêutica, a cor do comprimido e a via de administração do placebo também podem influenciar na resposta a placebo (Rajagopal. 2006; Buckelew et al., 1982 citado por Thompson 2005). Os autores descrevem que algumas formas farmacêuticas ou vias de administração tem um poder maior de induzir esse efeito. A injeção tem mais efeito que placebo oral, cápsula placebo é mais efetiva que comprimido, cápsulas coloridas são mais efetivas que brancas, comprimidos azuis são mais sedativos, comprimidos rosa são estimulantes e duas cápsulas de placebo são mais eficientes que uma apenas (Rajagopal, 2006).

$O$ contexto em que o placebo vai ser administrado envolve a postura do médico com o paciente e o ambiente. A relação médico-paciente é reconhecida como um fator importante para o efeito terapêutico (Blasi et al., 2001). Balint (1957) descreve que os médicos são as drogas mais usadas. Thomas (1994) relata que o médico pode influenciar positivamente no estado de saúde do paciente se ele tiver habilidade em se comunicar, empatia, comportamento e atitude (Benedetti et al., 2002). Os pacientes são mais propensos a apresentarem uma resposta a placebo se eles gostarem e confiarem no médico e se o tratamento for prescrito com entusiasmo e confiança (Thompson, 2005)

O ambiente onde o procedimento está sendo realizado, como por exemplo, a clínica, enfermaria hospitalar e consultório, bem como o tempo destinado à consulta são fatores importantes que podem influenciar na resposta ao tratamento ou na resposta a placebo (Thompson, 2005; Blasi et al., 2001). A credibilidade da clínica, do consultório e do tratamento é convertida em confiança para o paciente (Koshi et al., 2007). 


\subsection{Hipóteses do mecanismo do efeito placebo}

Nos ensaios clínicos farmacológicos e na prática clínica, o efeito placebo é bem conhecido, mas o entendimento da neurobiologia e neuropsicologia ainda são limitados (Benedetti et al., 2003). Muitos estudos vêm tentando elucidar os mecanismos psicobiológicos envolvidos na resposta a placebo e várias teorias têm sido propostas (Koshi et al., 2005; Moerman et al., 2002), como a de condicionamento (Geers et al., 2005), a da expectativa (Geers et al., 2004), e da perspectiva motivacional (Geers et al., 2005).

Thompson (2005) descreve um fator importante que deve ser considerado na resposta a placebo que é a melhora dos sintomas em função do curso natural da doença e não do placebo. Assim, no desenho dos ensaios clínicos que procuram determinar a eficácia de um novo fármaco, além do controle placebo, seria necessário incluir um grupo de pacientes que não receba nenhum tratamento. Por questões éticas isso nem sempre é possível e, de fato, raramente implementados nos estudos clínicos.

\subsubsection{Hipótese do condicionamento clássico}

O condicionamento clássico, também chamado de condicionamento respondente ou Pavloviano, resulta da combinação repetida de um estímulo neutro (condicionado) associado a um estímulo que evoque uma resposta (estimulo não condicionado) (Sadock et al., 2007).

Voudouris et al. (1985) propõem que na resposta a placebo o estímulo condicionado seria um medicamento que o sujeito recebe diversas vezes e em todas elas o resultado é positivo. O estímulo incondicionado seriam algumas características (cor, sabor e forma) do medicamento. Benedetti et al. (1997) citado por Koshi et al. (2007), demonstram essa associação com o seguinte exemplo: um paciente com dor de cabeça que toma regularmente aspirina (estímulo condicionado) pode associar a forma, cor e o gosto da aspirina (estímulo incondicionado) para o alívio da dor. Após várias associações, a dor poderia diminuir quando fosse dado ao paciente um placebo que se parecesse com a aspirina.

Voudouris et al. (1985) sugerem que o efeito de um tratamento pode ser maximizado se o médico ao prescrever um tratamento levar em consideração a 
experiência anterior do paciente com a droga prescrita e o que paciente espera do tratamento proposto.

\subsubsection{Hipótese da expectativa}

A teoria da expectativa, desenvolvida por Goldstein em 1962, postula que a resposta a placebo está relacionada à expectativa de melhora do paciente (Goldstein, 1962 citado por Koshi et al., 2007; Jensen et al., 1991).

A expectativa depende da percepção que o indivíduo tem do tratamento, ou seja, quando o sujeito acredita que o tratamento tem um grande potencial no alivio dos sintomas, a resposta tende a ser mais intensa (Rajagopal, 2006).

Um exemplo da relação expectativa do paciente e efeito placebo é o de um estudo clínico envolvendo dor que demonstrou que pacientes do sexo feminino responderam de forma significativamente superior a um analgésico, cuja marca é bastante popular em relação a um analgésico sem marca (Branthwaite e Cooper, 1981).

Em outro estudo, em pacientes com depressão maior, Krell et al. (2004) avaliaram a eficácia do tratamento de acordo com a expectativa que os sujeitos tinham do mesmo antes de iniciar o estudo, utilizando os seguintes critérios de respostas: 1) nenhum efeito; 2) algum efeito; ou 3) um efeito bom. Apenas duas pessoas responderam que não esperavam nenhum efeito e foram excluídas do estudo. No grupo que esperava um efeito bom a resposta para o tratamento foi de $90 \%$, sendo que no grupo que disse que esperava algum efeito a resposta foi apenas de $33 \%$.

Benedetti et al. (2003) observaram que uma indução verbal de expectativa feita de forma isolada, sem um pré-condicionamento, não gerou nenhuma uma resposta a placebo quando funções fisiológicas inconscientes estavam envolvidas (por exemplo, secreção de hormônios). Por outro lado, quando funções fisiológicas conscientes estavam envolvidas, como dor e função motora, a indução verbal de expectativa proporcionou um efeito de analgesia e melhora na função motora. 


\subsubsection{Hipótese da perspectiva motivacional}

A perspectiva motivacional, de acordo com Geers et al. (2005), seria resultado de um desejo ou objetivo que o sujeito tem em sentir-se melhor com o tratamento ou cooperar com o experimento ou com o profissional da saúde. O efeito placebo é mais provável de ocorrer quando o indivíduo tem um objetivo, e esse só será alcançado caso ele responda de uma maneira consistente a sua expectativa. Dessa forma, a perspectiva motivacional é tão importante quanto a expectativa e a associação desses dois fatores é fundamental para que o indivíduo perceba a experiência somática do efeito placebo (Geer et al., 2005).

A associação entre expectativa e perspectiva emocional é uma importante ferramenta para ser utilizada pelos profissionais de saúde porque pode proporcionar resultados mais positivos no tratamento de seus pacientes (Geers et al., 2005). Nas pesquisas clínicas essa associação é útil na interpretação dos dados das pesquisas clínicas obtidos nas condições controladas por placebo porque a motivação passaria a ser considerada uma variável no desenho do estudo.

Jensen et al. (1991) estudaram o efeito da motivação em estudantes de psicologia em resposta a uma pílula "sedativa" placebo. Nesse estudo, um grupo de voluntários foi motivado ou desmotivado a ter um aumento ou diminuição no desejo de responder ao sedativo, através da leitura de textos. Os resultados sugeriram que a motivação influencia a resposta placebo, uma vez que os sujeitos que foram encorajados a responder a um "sedativo placebo" tenderam a relatar um alto nível de sedação, ao contrário dos sujeitos que não foram igualmente motivados.

\subsection{Efeito nocebo}

O efeito nocebo, originado do latim, foi traduzido para o inglês como "I will harm" e refere-se a mudanças fisiológicas e/ou na sintomatologia que segue a administração de uma substância inativa que o paciente acredita ser um droga ativa (Barsky et al., 2002).

As hipóteses que tentam explicar o efeito nocebo são semelhantes às do efeito placebo. A expectativa do tratamento, ou seja, os sujeitos que antecipam efeitos colaterais desagradáveis antes mesmo de receber o medicamento são os mais prováveis de apresentá-los (Barsky et al., 2002). Outros fatores também são 
associados ao efeito nocebo como condicionamento, características individuais dos sujeito e a influência do contexto (Reeves et al., 2007; Barsky et al., 2002)

O efeito nocebo é observado pelo relato espontâneo de efeitos colaterais por cerca de $25 \%$ dos pacientes que recebem placebo (Shepherd, 1993), índice que aumenta quando os sujeitos são questionados sobre a sua ocorrência. Os mais freqüentes são sonolência $(25) \%$, fadiga (17\%) e queixas gastrointestinais $(16 \%)$ (Herzahaft, 1969).

\subsection{Estudos de neuroimagem}

Alguns autores vêm demonstrando alterações em áreas cerebrais nos indivíduos que apresentam resposta a placebo, através de técnicas de neuroimagem (Mayberg et al., 2002; De la fuente-Fernandez et al., 2002; Petrovic et al. 2002).

Estes estudos têm sugerido que o efeito placebo é mediado por ativação do sistema cerebral de recompensa (De la fuente-Fernandez et al., 2002). Petrovic et al. (2002) utilizaram tomografia por emissão de pósitrons (PET) e verificaram que áreas corticais envolvidas no controle da dor foram ativadas, tanto nos indivíduos respondedores a opióides quanto nos respondedores a placebo, após ambos terem recebido estímulos dolorosos de intensidade variável.

Mayberg et al. (2002), através do uso de PET, demonstraram uma associação entre a ativação dos córtices frontal e cingulado posterior com a melhora do humor, tanto em pacientes deprimidos respondedores a placebo quanto em respondedores a antidepressivos.

Lidstone et al. (2007) acreditam que os estudos de neuroimagens têm contribuido para o entendimento do mecanismo do efeito placebo em doenças neurológicas e psiquiátricas. Estes autores acreditam que não exista apenas um único mecanismo básico, mas que todos os mecanismos envolvidos têm em comum o componente da expectativa, no qual estaria envolvido o córtex pré-frontal dorso lateral esquerdo e a atividade dopaminérgica no estriado ventral. O envolvimento do estriado ventral também foi sugerido por De la Fuente-Fernandez et al. (2004), segundo os quais, o efeito placebo, gerado pela expectativa de um benefício clínico ou de recompensa ativa essa região do cérebro, que por sua vez irá liberar o neurotransmissor dopamina. 


\subsection{Variáveis genéticas}

As sensações de expectativa e recompensa envolvidas no efeito placebo sugerem o envolvimento do sistema dopaminérgico, em interação com o sistema serotonérgico, na ocorrência deste fenômeno (De la Fuentes et al., 2004). Tanto o sistema dopaminérgico quanto 0 serotonérgico estão relacionados com determinados padrões de resposta e comportamento exploratório e inibitório e que são descritos respectivamente no fator de personalidade busca de novidade e esquiva ao dano.

A associação dos sistemas de neurotransmissores com os mecanismos envolvidos na resposta a placebo sugere que variações (polimorfismos) em genes do sistema serotonérgico e dopaminérgico. Estudos sobre aspectos neurobiológicos do efeito placebo são ainda incipientes, no entanto, foram encontrados somente dois estudos associando variáveis genéticas à resposta placebo em pacientes com depressão maior (Durham et al., 2003; Sakul, 2004).

Durham et al. (2003) observaram que as variações genotípicas no polimorfismo na região promotora do gene que codifica o transportador de serotonina (5HTTLPR) podem estar envolvidas na resposta a placebo. Estes autores demonstraram que no grupo de respondedores a placebo a freqüência de indivíduos homozigotos para o alelo longo (L/L) foi menor que a freqüência de indivíduos com os alelos (L/S e L/S). Sakul (2004) obteve resultados semelhantes analisando o mesmo polimórfismo.

\subsection{Variáveis de personalidade}

A influência das características de personalidade na resposta a placebo tem sido descrita, porém a maioria dos estudos mostram resultados inconsistentes (Hyland et al., 2007).

Hutchison et al. (1999) observaram em um experimento com anfetamina e placebo que indivíduos com altos escores do fator de personalidade busca de novidade (tendência de ativação e iniciação de comportamentos, por estímulos novos e suscetibilidade comportamental à estimulação ambiental) perceberam mais efeitos psicoestimulantes, tanto no grupo que recebeu anfetamina, quanto no grupo que recebeu placebo. 
Geers et al. (2004) avaliaram a resposta a placebo em voluntários classificados como otimistas e pessimistas, de acordo com questionário "Revised Life Orientation Test" (LOT-R). Foi administrado placebo, porem informou-se aos voluntários que eles receberiam um medicamento que poderia provocar sintomas desagradáveis (tensão, irritabilidade e etc.). Os indivíduos classificados como pessimistas relataram os sintomas negativos sugeridos pelo pesquisador com maior freqüência que os otimistas.

As influências de características de personalidade também foi avaliada em estudos farmacológicos com estimulantes, sedativos e antidepressivos. Natrielli (2002) relatam que indivíduos com escores mais elevados do fator de personalidade busca de novidade apresentaram maior sensibilidade a sedativos e estimulantes, ou seja, foram mais facilmente sedados com benzodiazepínicos e excessivamente estimulados com anfetaminas.

Raby et al. (2005) aplicaram o "Questionário Tridimensional de Personalidade" (TPQ) em pacientes dependentes de metadona e avaliaram como os traços de personalidade dos indivíduos poderiam diferenciar a resposta ao tratamento com o antidepressivo sertralina por 12 semanas. Os pacientes que apresentaram escores mais elevados em persistência (tendência a persistir em responder de determinada forma, independente de frustração ou fadiga) e esquivos ao dano (tendência a inibir ou cessar comportamentos perante sinais e estímulos aversivos) e baixos escores em dependência de gratificação (tendência a responder de maneira intensa a sinais de recompensa, visando a obtenção de prêmios) tiveram melhores respostas ao tratamento quando comparados aos indivíduos com características de personalidade opostas.

\subsection{Variáveis genéticas e características de personalidade}

A relação entre os traços de personalidade e as variações genotípicas tem sido alvo de investigações nas ultimas duas décadas. A hipótese que características de personalidade eram resultados da confluência de herança genética e fatores ambientais é bastante antiga, aparecendo em textos clássicos de psiquiatria. $O$ modelo psicobiológico de temperamento e caráter relaciona os sistemas de neurotransmissores dopamina, serotonina e norepinefrina, com os fatores de 
temperamento, busca de novidade (BN), esquiva ao dano (ED) e dependência de gratificação (DG), respectivamente. Alterações nos genes (polimorfismos) podem modificar a atividade das proteínas envolvidas em padrões individuais de resposta comportamentais.

Em estudos recentes (Vormfelde et al., 2005; Tsai et al., 2004; Szekely et al. (2004) e Jonsson et al., 2003) observaram que indivíduos portadores de alelo 7 do gene do receptor D4 (DRD4, VNTR do exon III) apresentaram escores mais baixos em persistência e que indivíduos homozigotos para o alelo curto (ss) do promotor do gene do transportador de serotonina (5HTTLPR) apresentaram escores maiores em esquiva ao dano. As características de personalidade dos sujeitos desses estudos foram avaliadas, respectivamente, pelo Inventário de Temperamento e Caráter (ITCCloninger et al., 1996) e pelo Questionário tridimensional de Personalidade (TPQCloninger et al., 1993), ambos desenvolvidos à partir do modelo psicobiológico de Cloninger (1987).

Samochowiec et al. (2004) encontraram uma associação entre indivíduos que apresentavam uma freqüência maior para o alelo S/S do 5HTTLPR com baixos escores em dependência de gratificação e busca de novidade.

Segundo Noblett et al. (2005) apesar dos estudos iniciais terem sido promissores, as pesquisas que tentam correlacionar variações genotípicas com características de personalidade apresentam resultados ainda controversos. Esses autores acreditam que a falta de consistência se deva à diversidade étnica das amostras e ao seu tamanho reduzido. 


\section{OBJETIVOS}

a) Verificar se há característica de personalidades associadas à resposta a placebo em estudos com antidepressivos;

b) Verificar se há associação de polimorfismos em genes do sistema serotonérgico com resposta a placebo. 


\section{JUSTIFICATIVA}

O efeito placebo tem um papel fundamental nas pesquisas com medicamentos, principalmente naquelas que envolvem fármacos que alteram componentes psicológicos, como a dor e a depressão (De la Fuente-Fernandez et al., 2002). Um número significativo de indivíduos responde positivamente a placebo nessas pesquisas o que acaba colocando em dúvida a verdadeira eficácia do medicamento avaliado. O estudo é relevante, pois tenta avaliar como alguns componentes individuais, as variáveis genotípicas e as características de personalidade, podem estar envolvidos na resposta positiva a placebo em estudos com antidepressivos. 


\section{MATERIAIS E MÉTODOS}

\subsection{Sujeitos}

Indivíduos de ambos os sexos, de 21 a 60 anos de idade, que participaram de estudos clínicos com antidepressivos no Instituto de Psiquiatria do Hospital das Clínicas da Universidade de São Paulo (IPQ-HCFMUSP), no período de 2000 a 2005, e que foram randomizados aleatoriamente ao grupo que recebeu placebo, foram convidados a participar desta pesquisa. Foram excluídos os portadores condições clínicas ou que envolvessem prejuízo de funções cognitivas.

\subsection{Procedimentos de seleção da amostra}

A primeira etapa foi a identificação de estudos com antidepressivos envolvendo placebo, conduzidos no IPQ-HCFMUSP, no período de 2000 a 2005. Foram identificados 4 estudos, todos eles concluídos: dois em pacientes deprimidos, conduzidos no Grupo de Doenças Afetivas (GRUDA), um em pacientes fóbicos, desenvolvido no Ambulatório de Ansiedade (AMBAN) e um em voluntários sadios, conduzido no Laboratório de Investigações Médicas-23 (LIM-23).

A etapa seguinte foi entrar em contato com os pacientes e convidá-los a participar do presente estudo. Os dados dos voluntários sadios já estavam sendo coletados como parte do protocolo do estudo do qual participaram.

\subsubsection{Pacientes com diagnóstico de depressão}

Pacientes com diagnóstico de depressão maior, de acordo com os critérios da Diagnostic and Statistical Manual of Mental Disorders-IV (DSM-IV) da American Psychiatry Association, 1994, categorias 296.2 e 296.3 (Depressão maior moderado ou grave, sem características psicóticas) participaram de estudos com antidepressivos e placebo no Grupo de Doenças Afetivas (GRUDA).

De acordo com o DSM-IV, para diagnóstico de episódio depressivo os sintomas devem estar presentes num período mínimo de duas semanas durante as quais há humor deprimido, perda de interesses ou prazer por quase todas as atividades, acompanhados por pelo menos por quatro sintomas adicionais de 
depressão, como alterações no apetite ou no peso, alterações no sono e na atividade psicomotora (diminuição da energia; sentimento de desvalia ou culpa; dificuldade para pensar, concentrar-se ou tomar decisões; ou pensamentos recorrentes sobre morte ou ideação suicida, planos ou tentativas de suicídio).

Para confirmação diagnóstica, os pacientes foram entrevistados por psiquiatras treinados. $\mathrm{Na}$ inclusão preencheram a Escala de Avaliação para Depressão de Hamilton com no mínimo de 25 pontos (HAM-D).

No primeiro estudo os pacientes foram alocados de forma aleatória a um dos três grupos distintos: fluoxetina $20 \mathrm{mg} / \mathrm{d}$, hypericum perforatum $900 \mathrm{mg} / \mathrm{d}$ ou placebo. Os pacientes foram acompanhados semanalmente por até 52 semanas.

No segundo estudo os pacientes foram alocados aleatoriamente a mitazarpina 15 a $60 \mathrm{mg} / \mathrm{dia}$, ou fluoxetina 20 a $40 \mathrm{mg} / \mathrm{dia}$, ou placebo. Os pacientes foram acompanhados inicialmente por 8 semanas e depois através de visitas agendadas na fase de extensão.

\subsubsection{Pacientes com diagnóstico de fobia social}

Pacientes com diagnóstico de fobia social, de acordo com os critérios do DSM-IV participaram do estudo no Ambulatório de Ansiedade (AMBAN).

A fobia social é classificada como um transtorno de ansiedade, onde a característica essencial é o medo acentuado e persistente de situações sociais ou de desempenho nas qual o indivíduo poderia sentir vergonha. A exposição à situação social ou de desempenho provoca, quase que invariavelmente, uma resposta imediata de ansiedade, que pode assumir a forma de um ataque de pânico ligado à situação ou predisposto pela situação, interferindo significativamente na vida do indivíduo.

Os sintomas físicos em situações de falar, comer, beber ou escrever em público, podem ser palpitações, tremores, sudorese, desconforto gastrintestinal, diarréia, tensão muscular, rubor facial, confusão até um ataque de pânico.

Para serem incluídos no estudo, os pacientes foram entrevistados por psiquiatras treinados para confirmação do diagnóstico e avaliados pela escala de Impressão Clínica Global (CGI), sendo incluídos no estudo os considerados com gravidade moderada a intensa. 
Os pacientes do estudo foram acompanhados semanalmente por 12 semanas recebendo um dos quatro tratamentos: antidepressivo setralina; sertralina + terapia cognitivo comportamental (TCC); placebo + TCG; placebo. Foi considerado para o presente estudo apenas o grupo que recebeu placebo.

\subsubsection{Sujeitos sem diagnóstico psiquiátrico}

Os sujeitos foram considerados sadios, de acordo com os critérios do "Estudo Psicobiológico da Regulação Emocional a Partir dos Efeitos de Antidepressivos" (Projeto Humor): sem nenhuma queixa de sintomatologia psiquiátrica atual ou progressiva, inclusive em parentes de $1^{\circ} \mathrm{grau}$, ausência de sintomas sugestivos de uma ampla gama de doenças sistêmicas (cardíaca, renal, pulmonar, hepática, etc.), ausência de doença médica atual com comorbidades psiquiátricas ou história de tentativa de suicídio, entre outras (gravidez, amamentação, parto nos últimos 6 meses)

Nesse estudo os voluntários sadios receberam baixas doses do antidepressivo clomipramina ou placebo e foram acompandos semanalmente por 8 semanas.

\subsection{Determinação dos critérios para os respondedores}

Os sujeitos foram subdivididos em respondedores e não respondedores a placebo de acordo com os critérios atribuídos para cada estudo:

\section{- Pacientes deprimidos}

Indivíduos que apresentaram uma melhora de 50\% na Escala de Avaliação para Depressão de Hamilton em relação à basal.

\section{- Pacientes fóbicos}

Indivíduos que apresentaram no item Melhora Global da escala Impressão Clínica Global (CGI) avaliações correspondentes a melhora mínima e muita melhora

- Sujeitos sadios

Foram considerados respondedores os indivíduos que apresentaram melhora em sintomas individuais, tais como ansiedade e irritação (resposta parcial) e os respondedores totais aqueles que apresentaram melhora em três de quatro áreas (resposta plena): tolerância e diminuição da irritabilidade, eficiência e auto controle, 
sensação de bem estar, sensação de estar diferente do habitual.

\subsection{INSTRUMENTOS}

\subsubsection{Inventário de Temperamento e Caráter (ITC)}

O Inventário de Temperamento e Caráter (ITC) foi desenvolvido por Cloninger et al. (1993) e validado para o português por Fuentes et al. (2000). Consta de 240 afirmações que devem ser respondidas com verdadeiro ou falso. As afirmações descrevem opiniões, interesses e outros sentimentos pessoais. O ITC avalia as características de personalidade através de 4 fatores de temperamento e 3 fatores de caráter. Os valores normativos de cada fator foram baseados em um estudo realizado por Cloninger et al. (2003) em amostra americana (300 indivíduos, 150 homens, idade entre 18 e 47 anos, da população de St Louis-Missouri).

\section{A. Fatores de temperamento:}

A1. Busca de Novidades (BN, os escores variam de 0 a 40; escore normativo: 19,2 \pm 6,0): tendência hereditária de ativação e iniciação de comportamentos, por estímulos novos e suscetibilidade comportamental à estimulação ambiental. A2. Esquiva ao Dano (ED, os escores variam de 0 a 35; escore normativo: 12,6 $\pm 12,6)$ : tendência hereditária a inibir ou cessar comportamentos perante sinais e estímulos aversivos.

A3. Dependência de Gratificação (DG, os escores variam de 0 a 24; escore normativo: $15,5 \pm 4,4)$ : tendência hereditária a responder de maneira intensa a sinais de recompensa, visando à obtenção de prêmios.

A4. Persistência ( $P$, os escores variam de 0 a 8; escore normativo: 5,6 $\pm 1,9$ ): tendência hereditária a persistir em responder de determinada forma, independente de frustração ou fadiga.

\section{B. Fatores de Caráter:}


B1. Autodirecionamento ( $A D$, os escores variam de 0 a 44; escore normativo: $30,7 \pm 7,5$ ): identificação de si mesmo como um indivíduo autônomo.

B2. Cooperatividade ( $C$, os escores variam de 0 a 42; escore normativo: $32,3 \pm$ 7,2): identificação de si mesmo como parte integrante da sociedade e da humanidade.

B3. Autotranscendência (AT, os escores variam de 0 a 33; escore normativo: \pm 19,2 $\pm 6,3$ ): identificação de si mesmo como parte integrante de todas as coisas, de um modo todo interdependente. Caracteriza-se como uma medida do idealismo do indivíduo em oposição ao convencionalismo.

\subsubsection{Determinação de Marcadores Genéticos}

Foram escolhidos 3 genes do sistema serotonérgico para a análise de polimorfismos: o gene que codifica o transportador de serotonina (SLC6A4), o gene que codifica o receptor de serotonina subtipo 2A (HTR2A) e o gene que codifica o receptor de serotonina subtipo $1 \mathrm{~B}$ (HTR1B).

Para que fosse realizada uma análise de polimorfismos que cobrisse toda a extensão dos genes selecionados seria necessário genotipar 14 single nucleotide polymorphisms (tag SNPs) no SLC6A4, 40 tag SNPs no HTR2A e dois tag SNPs no HTR1B, de acordo com cálculos realizados no programa Haploview, utilizando um $\mathrm{r}^{2}$ de 0,6 e optando-se por agressive tagging para genotipagem do menor número possível de polimorfismos. Para estes cálculos, foram os dados do projeto HAPMAP (www.hapmap.org). No entanto, foi possível genotipar apenas SNPs cujos primers estavam disponíveis no laboratório de Genética do LIM-23 (Laboratório de Psicofarmacologia), IPqHC-FMUSP 


\subsubsection{Genotipagem}

Foram selecionados polimorfismos em genes do sistema serotonérgico com demonstrada atividade funcional ou previamente associados a traços de personalidade (Lochner et al., 2007) e respondedores a placebo (Sakul, 2004). As genotipagens foram realizadas pela equipe técnica do Laboratório de Genética do LIM-23 do IPqHC-FMUSP.

A amplificação dos fragmentos polimórficos dos genes estudados foi obtida por técnica de reação em cadeia de polimerase (PCR). Para cada um dos polimorfismos estudados foram seguidos os protocolos específicos de PCR descritos a seguir. Os tamanhos dos fragmentos foram estimados através de comparação com um marcador de tamanho de DNA (Ladder 100bp - Gibco). Amostras com genótipos ambíguos foram regenotipadas. Posteriormente, $10 \%$ da amostra foi selecionada aleatoriamente e regenotipada para controle de qualidade. A leitura dos genótipos foi feita sem que houvesse conhecimento sobre o grupo de proveniência.

\subsubsection{Gene do Transportador de Serotonina (SLC6A4)}

Localiza-se no cromossomo 17q11.1-q12, sendo constituído por $31 \mathrm{~kb}$, e contendo 14 exons (Lesch et al., 1996). Foi genotipado o polimorfismo localizado na região promotora do gene, constituído por uma inserção/deleção de 44 bp 5HTTLPR (Heils et al., 1996; Lesch et al., 1996). Este polimorfismo está localizado a cerca de $1 \mathrm{~kb}$ "upstream" do início do sítio de transcrição.

Foi seguido o protocolo de PCR conforme descrição de Cook et al. (1997), utilizando 50 ng de DNA genômico, tampão de PCR Gibco $(2 \mu l)$, PCR enhancer Invitrogen $(2,0 \mu \mathrm{l})$, primer forward 5'-TGA ATG CCA GCA CCT AAC CC-3', primer reverse R1 5' - TTC TGG TGC CAC CTA GAC GC-3' (1,5 $\mu$ le cada), dATP, dTTP,

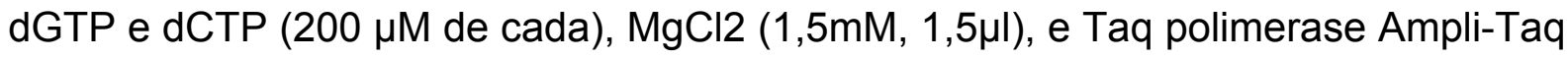
(1 U). O ciclo de PCR consistiu em uma fase de desnaturação a $95^{\circ} \mathrm{C}$ por 3 minutos, uma fase de amplificação de 40 ciclos a $95^{\circ} \mathrm{C}$ por 30 segundos, $61^{\circ} \mathrm{C}$ por 30 segundos, $71^{\circ} \mathrm{C}$ por 1 minuto, e uma fase de extensão a $72{ }^{\circ} \mathrm{C}$ por 10 minutos. Em seguida, os produtos de PCR foram incubados a $37^{\circ} \mathrm{C}$ por 12 horas com a enzima Mspl $(0,5 \mu \mathrm{l})$. Os fragmentos assim produzidos foram denominados:

- Alelo L (longo): 454bp 
- Alelo $S$ (curto): $406 \mathrm{bp}$

Os produtos de PCR foram separados por eletroforese em gel de agarose a $2,5 \%,(100 \mathrm{~V}, 1,5$ hora $)$.

\subsubsection{Gene do Receptor de Serotonina Subtipo 1B (5HT1B)}

O gene que codifica o receptor 5HT1B encontra-se no cromossomo $6 \mathrm{q} 13$ (Mochizuki et al., 1992), consistindo de apenas 1 exon, não contendo nenhuma seqüência intrônica, com um quadro de leitura de 390 aminoácidos com sete regiões hidrofóbicas, típicas dos receptores acoplados à guanina (Demchyshyn et al., 1992). Foi genotipado o polimorfismo constituído por uma substituição de guanina por citosina no nucleotídeo 861, denominado 5HT1B G861C (Lappalainen et al., 1995).

Na realização do PCR foram utilizados 50ng de DNA genômico, tampão de PCR Gibco, primer forward 5HT1B-A: 5' - GAA ACA GAC GCC CAA CAG GAC - 3', primer reverse 5HT1B-B: 5' -CCA GAA ACC GCG AAA GAA GAT- 3' $(1,5 \mu \mathrm{M})$, MgCl2, dATP, dTTP, dGTP e dCTP (200 $\mu \mathrm{M}$ de cada), Taq Polimerase Ampli-Taq (1U). A fase de desnaturação ocorreu a $95{ }^{\circ} \mathrm{C}$ por 3 minutos, seguida de amplificação durante 30 ciclos de $95^{\circ} \mathrm{C}$ por 30 segundos, $57^{\circ} \mathrm{C}$ por 30 segundos, 72 ${ }^{\circ} \mathrm{C}$ por 30 segundos, e uma extensão de $72{ }^{\circ} \mathrm{C}$ por 7 minutos. Os produtos de PCR foram digeridos com as enzimas Hinll e BSA durante 12 horas a $37^{\circ} \mathrm{C}$. Foi realizada eletroforese em gel de agarose 2,5\% (100V, 1 hora) e visualizou-se os seguintes alelos:

- Alelo longo: $548 \mathrm{bp}$

- Alelo curto: $406+142$ bp 


\subsubsection{Gene do Receptor de Serotonina subtipo 2A (HTR2A)}

O gene que codifica o receptor 5HT2A encontra-se no cromossomo 13q14q21, consistindo de mais de $20 \mathrm{~kb}$, e de 3 exons e 2 introns, com um comprimento de $20 \mathrm{~kb}$ (Chen et al., 1992). Foram genotipados os seguintes polimorfismos:

- $\quad$ HTR2A (T102C): Localizado no exon 1, é constituído por uma substituição de timina por citosina no nucleotídeo 102 do gene (Warren et al., 1993). O protocolo de PCR (Warren et al., 1993) utilizou 150 ng de DNA genômico, tampão de PCR Gibco, primer forward 5' - GAC ACC AGG CTC TAC AGT AAT GAC - 3', primer reverse 5'CGA CTG TCC AGT TAA ATG CAT CAGA- 3' (1,5 $\mu$ lde cada), $\mathrm{MgCl}_{2}$, dATP, dTTP, dGTP e dCTP (200 $\mu \mathrm{M}$ de cada), Taq Polimerase Ampli-Taq (1 U). A etapa de desnaturação realizada a $95^{\circ} \mathrm{C}$ durante 3 minutos, seguida de amplificação durante 35 ciclos de $94^{\circ} \mathrm{C}$ por 30 segundos, $61^{\circ} \mathrm{C}$ por 30 segundos, $72{ }^{\circ} \mathrm{C}$ por 30 segundos, com uma extensão de $72{ }^{\circ} \mathrm{C}$ por 7 minutos. Foi realizada digestão com a enzima de restrição Mspl por 12 horas a $37^{\circ} \mathrm{C}$. Os produtos foram visualizados após eletroforese em gel de agarose a 2,5\% (100 V, 1,5 hora). Os alelos visualizados foram:

- Alelo 102T: 342bp

- Alelo 102C: $216+126$ bp

- HTR2A (C516T): Localizado no exon 2, resulta de uma substituição de citosina por timina no nucleotídeo 516 do gene (Arranz et al., 1995). O protocolo de PCR foi realizado com 100 ng de DNA genômico, tampão de PCR Gibco, primer forward 5'-GGA TAG GGA TCC ATG TGC TC-3', primer reverse 5'-TGT GGT GGA

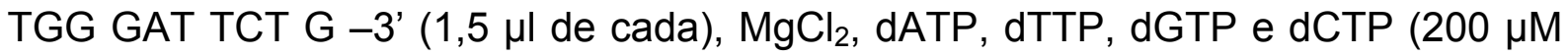
de cada), Taq Polimerase Ampli-Taq (1 U). A etapa de desnaturação realizada a 95 ${ }^{\circ} \mathrm{C}$ durante 3 minutos, seguida de amplificação durante 40 ciclos de $94{ }^{\circ} \mathrm{C}$ por 30 segundos, $61^{\circ} \mathrm{C}$ por 30 segundos, $72{ }^{\circ} \mathrm{C}$ por 30 segundos, com uma extensão de 72 ${ }^{\circ} \mathrm{C}$ por 7 minutos. Foi realizada digestão com a enzima de restrição Sas96I por 12 horas a $37^{\circ} \mathrm{C}$. Os produtos foram visualizados após eletroforese em gel de agarose a 2,5\% (100 V, 1,5 hora). Os alelos observados foram: 
- Alelo T516: 195 bp

- Alelo C516: $106+87$ bp

\subsection{ANÁLISES DOS DADOS}

\subsubsection{Variáveis de personalidade}

Foi aplicado o teste de LEVENE para verificar a homogeneidade dos escores das variáveis de personalidade nos dois grupos (respondedores e não respondedores a placebo) e posteriormente o teste $\mathrm{t}$ para verificar as diferenças significativas em relação à resposta a placebo na amostra total e nas amostras individuais em cada grupos de sujeitos (normais, deprimidos e fóbicos). Também foi aplicada uma análise de variância (ANOVA) para identificar as diferenças existentes entre os sujeitos sadios e pacientes psiquiátricos. O ultimo teste estatístico aplicado foi uma análise de regressão multivariada para verificar se alguma das variáveis estudadas (sexo, idade, diagnóstico, escolaridade) poderia exercer uma influência mais acentuada na associação dos fatores de personalidade com a resposta a placebo.

\subsubsection{Variáveis genéticas}

A análise univariada dos polimorfismos foi realizada no programa UNPHASED versão 3.0.10 (Dudbridge, 2003; Dudbridge, 2006). Para o teste de associação de alelos e genótipos utilizando como variável dependente a resposta placebo, o programa utiliza o teste de $X^{2}$ modificado por Dudbridge (2006) e compara o efeito de cada alelo/genótipo em relação ao alelo/genótipo de referência (Dudbridge et al., 2006). Caso o alelo/genótipo de referência esteja associado à variável dependente, o programa permite que outra referência seja especificada.

A análise estatística que envolve os dados de genética molecular foi realizada em colaboração com a Dra. Daniela S. S. Lobo, do Center for Addiction and Mental Health na Universidade de Toronto, Canadá. 


\section{RESULTADOS}

Na tabela 1 estão apresentados o número e percentual de respondedores e não respondedores a placebo na amostra total e sub.

Tabela 1 - Número e percentual de respondedores e não respondedores a placebo na amostra total e sub-grupos

\begin{tabular}{l|c|c}
\hline & $\mathbf{n}$ & $\mathbf{\%}$ \\
\hline Todos os sujeitos & $\mathbf{5 7}$ & \\
\hline Respondedores a placebo & 17 & 29.82 \\
Não respondedores a placebo & 40 & 70,17 \\
\hline Pacientes deprimidos & $\mathbf{1 4}$ & \\
Respondedores a placebo & 4 & 28,57 \\
Não respondedores a placebo & 10 & 71,42 \\
\hline Pacientes fóbicos & $\mathbf{2 2}$ & \\
Respondedores a placebo & 6 & 27,27 \\
Não respondedores a placebo & 16 & 72,72 \\
& & \\
\hline Sujeitos normais & $\mathbf{2 1}$ & \\
Respondedores a placebo & 6 & 28,57 \\
Não respondedores a placebo & 15 & 71,42 \\
\hline
\end{tabular}

\subsection{Comparação das características sócio-demográficas entre os respondedores e não respondedores a placebo}

A tabela 2 mostra a comparação das características sócio-demográficas entre os sujeitos que responderam a placebo e os que não responderam a placebo na amostra total $(n=57)$. Não houve diferenças estatisticamente significativa entre os grupos, de acordo com a resposta a placebo, em relação à idade, escolaridade e ao gênero.

Tabela 2 - Características sócio-demográficas dos respondedores e não respondedores a placebo na amostra total $(n=57)$ 


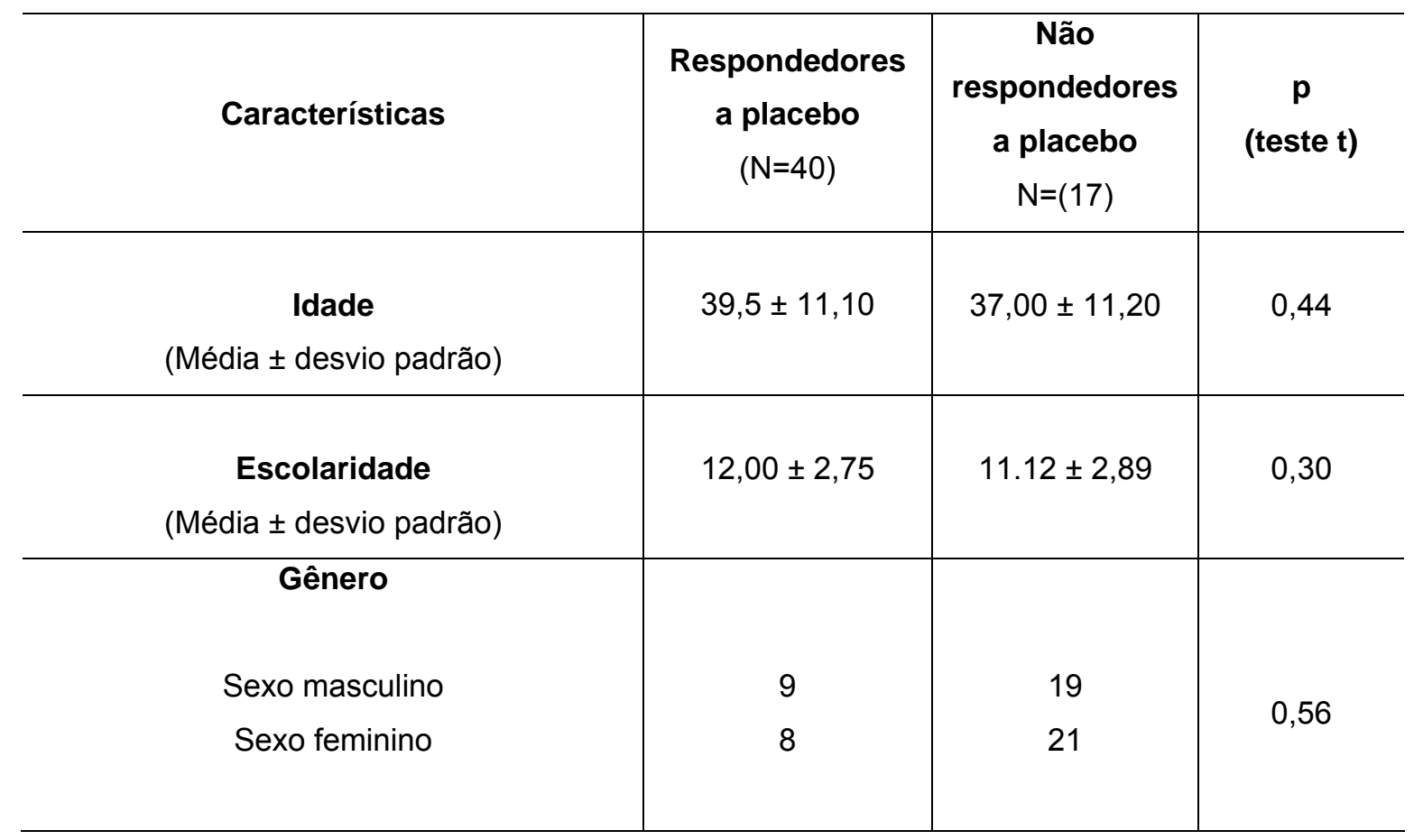

\subsection{Variáveis de Personalidade}

A tabela 3 e a figura 1 apresentam os escores médios no Inventário de Temperamento e Caráter (ITC) dos grupos que participaram do estudo (sujeitos normais, pacientes fóbicos e pacientes deprimidos), independente da resposta a placebo. A figura 1 também apresenta uma linha com escores normativos, de acordo com Cloninger et al. (2004).

A análise de variância (ANOVA) mostrou que existem diferenças significativas entre os grupos em quatro dos sete fatores de personalidade. Os sujeitos normais apresentaram escores significativamente menores no fator de personalidade esquiva ao dano e maiores para o fator de personalidade autodirecionamento que os pacientes fóbicos e deprimidos. Os sujeitos normais também apresentaram escores significativamente maiores no fator de personalidade cooperatividade que os pacientes fóbicos e, escores significativamente menores para o fator de personalidade autotranscendência que os pacientes deprimidos. 
Tabela 3 - Escores médios no Inventário de Temperamento e Caráter (ITC) dos sujeitos normais e pacientes fóbicos e deprimidos

\begin{tabular}{|c|c|c|c|c|c|}
\hline Dimensões de Personalidade & Média \pm EPM & $\mathbf{F}$ & P1 & $\begin{array}{l}\text { Comparação } \\
\text { entre grupos }\end{array}$ & P2 \\
\hline \multicolumn{6}{|l|}{ BN - Busca de novidade } \\
\hline Sujeitos normais & $18,14 \pm 0,91$ & \multirow{3}{*}{1,34} & \multirow{3}{*}{0,26} & $S N \times P F$ & 0,24 \\
\hline Pacientes fóbicos & $15,77 \pm 1,11$ & & & $S N \times P D$ & 0,86 \\
\hline Pacientes deprimidos & $17,29 \pm 1,26$ & & & $P D \times P F$ & 0,62 \\
\hline \multicolumn{6}{|l|}{ ED - Esquiva ao dano } \\
\hline Sujeitos normais & $9,67 \pm 0,94$ & \multirow{3}{*}{38,82} & \multirow{3}{*}{0,00} & $\mathrm{SN} \times \mathrm{PF}$ & 0,00 * \\
\hline Pacientes fóbicos & $22,50 \pm 1,01$ & & & $S N \times P D$ & 0,00 * \\
\hline Pacientes deprimidos & $18,64 \pm 1,52$ & & & $P D \times P F$ & 0,06 \\
\hline \multicolumn{6}{|l|}{ DG - Dependência de Gratificacão } \\
\hline Sujeitos normais & $14,95 \pm 0,82$ & \multirow{3}{*}{0,32} & \multirow{3}{*}{0,72} & $\mathrm{SN} \times \mathrm{PF}$ & 0,85 \\
\hline Pacientes fóbicos & $14,41 \pm 0,58$ & & & $S N \times P D$ & 0,71 \\
\hline Pacientes deprimidos & $14,07 \pm 0,88$ & & & $P D \times P F$ & 0,95 \\
\hline \multicolumn{6}{|l|}{ P - Persistência } \\
\hline Sujeitos normais & $4,71 \pm 0,36$ & \multirow{3}{*}{0,35} & \multirow{3}{*}{0,70} & $\mathrm{SN} \times \mathrm{PF}$ & 0,74 \\
\hline Pacientes fóbicos & $4,32 \pm 0,39$ & & & $S N \times P D$ & 0,76 \\
\hline Pacientes deprimidos & $4,29 \pm 0,46$ & & & $P D \times P F$ & 0,99 \\
\hline \multicolumn{6}{|l|}{ AD - Autodirecionamento } \\
\hline Sujeitos normais & $37,71 \pm 0,90$ & \multirow{3}{*}{12,78} & \multirow{3}{*}{0,00} & $\mathrm{SN} \times \mathrm{PF}$ & 0,00 * \\
\hline Pacientes fóbicos & $27,64 \pm 1,18$ & & & $S N \times P D$ & 0,008 * \\
\hline Pacientes deprimidos & $30,57 \pm 1,69$ & & & $P D \times P F$ & 0,40 \\
\hline \multicolumn{6}{|l|}{$\underline{C \text {-Cooperatividade }}$} \\
\hline Sujeitos normais & $34,00 \pm 0,75$ & \multirow{3}{*}{7,11} & \multirow{3}{*}{0,002} & $\mathrm{SN} \times \mathrm{PF}$ & 0,001 * \\
\hline Pacientes fóbicos & $29,14 \pm 1,16$ & & & $S N \times P D$ & 0,22 \\
\hline Pacientes deprimidos & $31,57 \pm 0,74$ & & & $P D \times P F$ & 0,22 \\
\hline \multicolumn{6}{|l|}{ T-Autotranscendência } \\
\hline Sujeitos normais & $11,00 \pm 1,32$ & \multirow{3}{*}{6,27} & \multirow{3}{*}{0,004} & $S N \times P F$ & 0,97 \\
\hline Pacientes fóbicos & $11,41 \pm 1,37$ & & & $S N \times P D$ & 0,006 * \\
\hline Pacientes deprimidos & $18,00 \pm 1,64$ & & & $\mathrm{PD} \times \mathrm{PF}$ & 0,09 \\
\hline
\end{tabular}

$\mathrm{SN}=$ sujeitos normais; $\mathrm{PF}=$ pacientes fóbicos; $\mathrm{PD}=$ pacientes deprimidos.

$\left(^{*}\right)$ Estatisticamente significativo $(p<0,05)$

P1= Nível de significância da comparação entre grupos (SN, PF e PD) da ANOVA.

$\mathrm{P} 2=$ Total entre grupos de pacientes (teste $\mathrm{t}$ ) 


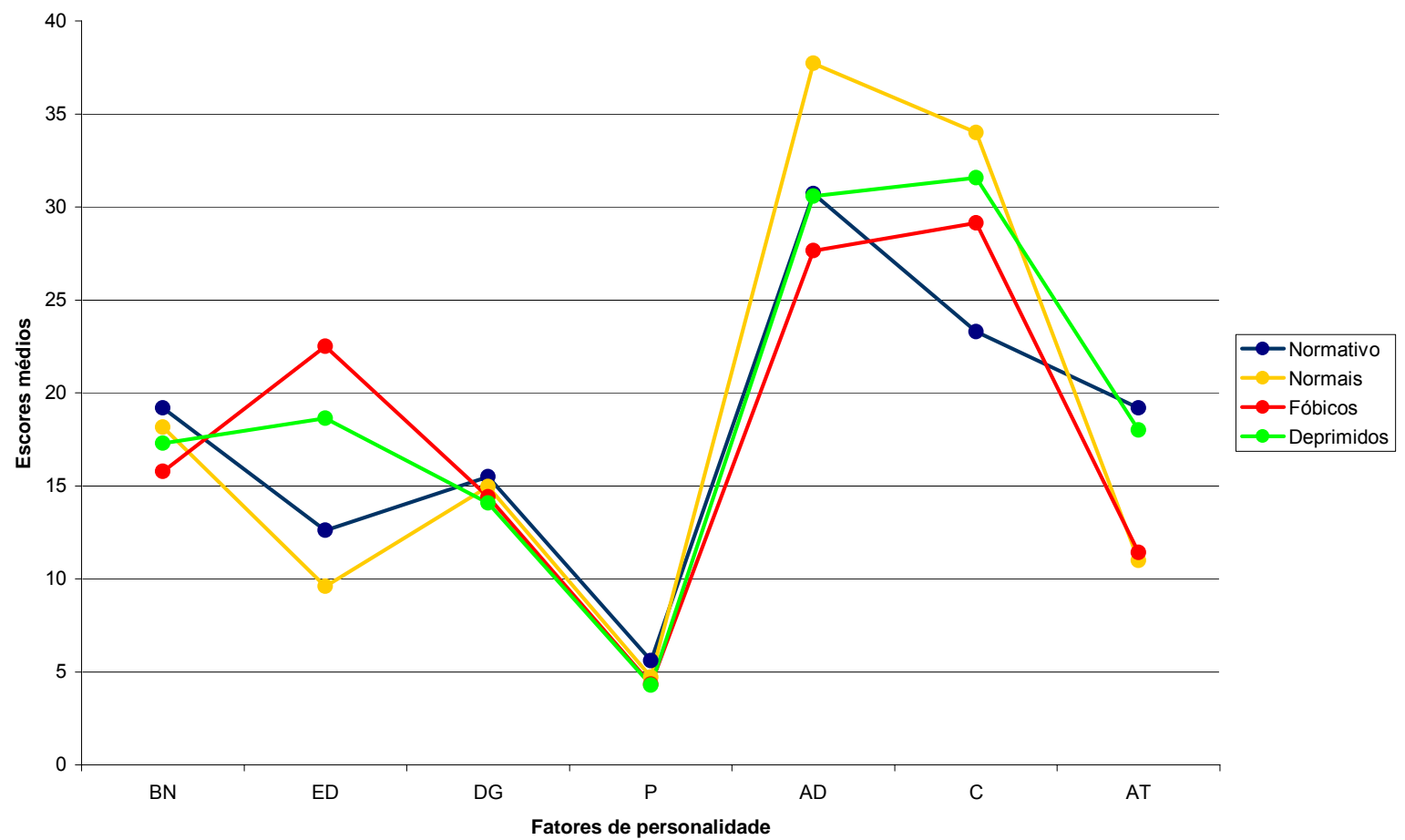

Figura 1 - Escores médios dos fatores de personalidade no Inventário de Temperamento e Caráter (ITC) dos diferentes grupos de sujeitos (normais, fóbicos e deprimidos)

Normativo: Escores normativos, de acordo com Cloninger et al., (2003)

BN: Busca de novidade; ED: Esquiva ao dano; DG: Dependência de gratificação; P: Persistência; AD: Autodirecionamento; C: Cooperatividade; AT: Autotranscendência.

As tabelas de 4 a 6 mostram os escores médios no Inventário de Temperamento e Caráter (ITC) em cada grupo de sujeitos individualmente As únicas diferenças estatisticamente observadas foram nos fatores de personalidade dependência de gratificação dos sujeitos normais e autotranscendência dos pacientes deprimidos. Em ambos os fatores, os escores dos respondedores foram maiores que os dos não respondedores a placebo. 
Tabela 4 - Escores médios no Inventário de Temperamento e Caráter dos respondedores $(n=6)$ e não respondedores $(n=15)$ a placebo no grupo de sujeitos normais

\begin{tabular}{l|c|c}
\hline \multicolumn{1}{c|}{ Dimensões de Personalidade } & Média \pm EPM & $\mathbf{p}$ \\
\hline BN - Busca de novidade & $20,33 \pm 1,14$ & 0,07 \\
Respondedores a placebo & $17,27 \pm 1,14$ & \\
Não respondedores a placebo & $10,00 \pm 1,25$ & 0,79 \\
\hline ED - Esquiva ao dano & $9,53 \pm 1,21$ & \\
Respondedores a placebo & $17,17 \pm 0,94$ & $0,04^{*}$ \\
Não respondedores a placebo & $14,07 \pm 1,02$ & \\
\hline DG - Dependência de Gratificaç̃o & & \\
Respondedores a placebo & $4,83 \pm 0,70$ & 0,84 \\
Não respondedores a placebo & $4,67 \pm 0,44$ & \\
\hline P - Persistência & $37,67 \pm 1,35$ & 0,97 \\
Respondedores a placebo & $37,73 \pm 1,16$ & \\
Não respondedores a placebo & $34,33 \pm 0,61$ & 0,16 \\
\hline AD - Autodirecionamento & $33,87 \pm 1,03$ & \\
Respondedores a placebo & $14,50 \pm 2,28$ & \\
Não respondedores a placebo & $9,60 \pm 1,36$ & \\
\hline C - Cooperatividade & & \\
Respondedores a placebo & Não respondedores a placebo & \\
\hline AT - Autotranscendência & \\
Respondedores a placebo & & \\
\hline Não respondedores a placebo & & \\
\hline
\end{tabular}

* Estatisticamente significativo do teste $t(p<0,05)$ 
Tabela 5 - Escores médios no Inventário de Temperamento e Caráter dos respondedores $(n=6)$ e não respondedores $(n=16)$ a placebo do grupo de pacientes com fobia social

\begin{tabular}{|c|c|c|}
\hline Dimensões de Personalidade & Média \pm EPM & $\mathbf{p}$ \\
\hline \multicolumn{3}{|l|}{ BN - Busca de novidade } \\
\hline Respondedores a placebo & $18,17 \pm 1,88$ & 0,18 \\
\hline Não respondedores a placebo & $14,88 \pm 1,32$ & \\
\hline \multicolumn{3}{|l|}{ ED - Esquiva ao dano } \\
\hline Respondedores a placebo & $21,83 \pm 1,51$ & 0,65 \\
\hline Não respondedores a placebo & $22,75 \pm 1,29$ & \\
\hline \multicolumn{3}{|l|}{ DG - Dependência de Gratificação } \\
\hline Respondedores a placebo & $13,33 \pm 0,67$ & 0,16 \\
\hline Não respondedores a placebo & $14,81 \pm 0,75$ & \\
\hline \multicolumn{3}{|l|}{ P-Persistência } \\
\hline Respondedores a placebo & $4,17 \pm 0,70$ & 0,81 \\
\hline Não respondedores a placebo & $4,38 \pm 0,49$ & \\
\hline \multicolumn{3}{|l|}{ AD - Autodirecionamento } \\
\hline Respondedores a placebo & $25,17 \pm 3,80$ & 0,45 \\
\hline Não respondedores a placebo & $28,56 \pm 2,08$ & \\
\hline \multicolumn{3}{|l|}{ C-Cooperatividade } \\
\hline Respondedores a placebo & $28,50 \pm 2,32$ & 0,75 \\
\hline Não respondedores a placebo & $29,38 \pm 1,38$ & \\
\hline \multicolumn{3}{|l|}{ AT- Autotranscendência } \\
\hline Respondedores a placebo & $14,50 \pm 3,14$ & 0,25 \\
\hline Não respondedores a placebo & $10,25 \pm 1,14$ & \\
\hline
\end{tabular}


Tabela 6 - Escores médios no Inventário de Temperamento e Caráter dos respondedores $(n=4)$ e não respondedores $(n=10)$ a placebo do grupo de pacientes com depressão

\begin{tabular}{|c|c|c|}
\hline Dimensões de Personalidade & Média \pm EPM & $\mathbf{p}$ \\
\hline \multicolumn{3}{|l|}{ BN - Busca de novidade } \\
\hline Respondedores a placebo & $21,00 \pm 1,91$ & 0,06 \\
\hline Não respondedores a placebo & $15,80 \pm 1,38$ & \\
\hline \multicolumn{3}{|l|}{ ED - Esquiva ao dano } \\
\hline Respondedores a placebo & $15,80 \pm 1,25$ & 0,11 \\
\hline Não respondedores a placebo & $19,80 \pm 1,99$ & \\
\hline \multicolumn{3}{|l|}{ DG - Dependência de Gratificação } \\
\hline Respondedores a placebo & $16,00 \pm 1,47$ & 0,18 \\
\hline Não respondedores a placebo & $13,30 \pm 1,03$ & \\
\hline \multicolumn{3}{|l|}{ P - Persistência } \\
\hline Respondedores a placebo & $5,25 \pm 1,11$ & 0,32 \\
\hline Não respondedores a placebo & $3,90 \pm 0,45$ & \\
\hline \multicolumn{3}{|l|}{ AD - Autodirecionamento } \\
\hline Respondedores a placebo & $30,50 \pm 1,19$ & 0,97 \\
\hline Não respondedores a placebo & $30,60 \pm 2,38$ & \\
\hline \multicolumn{3}{|l|}{$\underline{\mathrm{C} \text {-Cooperatividade }}$} \\
\hline Respondedores a placebo & $31,25 \pm 1,75$ & 0,82 \\
\hline Não respondedores a placebo & $31,70 \pm 0,84$ & \\
\hline \multicolumn{3}{|l|}{ AT - Autotranscendência } \\
\hline Respondedores a placebo & $23,25 \pm 1,25$ & $0,007^{*}$ \\
\hline Não respondedores a placebo & $15,90 \pm 1,87$ & \\
\hline
\end{tabular}

* Estatisticamente significativodo teste $t(p<0,05)$

Na tabela 7 são mostrados os escores médios dos fatores de personalidade dos respondedores e não respondedores a placebo considerando a amostra total $(n=57)$. Os respondedores apresentaram escore significativamente maior para os fatores de personalidade busca de novidade e autotranscendência quando comparados aos não respondedores.

A figura 2 apresenta o gráfico dos dados descritos nas tabelas 7, onde os respondedores a placebo apresentaram escore significativamente maior para os fatores de personalidade busca de novidade e autotranscendência quando comparados aos não respondedores 
Para verificar que variáveis estiveram associadas à resposta placebo foi realizada uma análise de regressão multivariada, na qual as variáveis estudadas (idade, sexo, escolaridade, diagnóstico e fatores de personalidade). Os resultados na tabela 8 mostraram uma associação estatisticamente significativa apenas com os fatores de personalidade busca de novidade e esquiva ao dano.

Tabela 7 - Escores médios no Inventário de Temperamento e Caráter dos respondedores $(n=16)$ e não respondedores $(n=41)$ a placebo comparando-se todos os sujeitos do estudo

\begin{tabular}{|c|c|c|}
\hline Dimensões de Personalidade & Média \pm EPM & $\mathbf{p}$ \\
\hline $\begin{array}{l}\text { BN - Busca de novidade } \\
\text { Respondedores a placebo } \\
\text { Não respondedores a placebo }\end{array}$ & $\begin{array}{l}19,69 \pm 0,94 \\
15,98 \pm 0,74\end{array}$ & $0,007^{*}$ \\
\hline $\begin{array}{l}\text { ED - Esquiva ao dano } \\
\text { Respondedores a placebo } \\
\text { Não respondedores a placebo }\end{array}$ & $\begin{array}{l}15,88 \pm 1,51 \\
17,20 \pm 1,24\end{array}$ & 0,55 \\
\hline $\begin{array}{l}\text { DG - Dependência de Gratificação } \\
\text { Respondedores a placebo } \\
\text { Não respondedores a placebo }\end{array}$ & $\begin{array}{l}15,44 \pm 0,78 \\
14,17 \pm 0,54\end{array}$ & 0,18 \\
\hline $\begin{array}{l}\text { P - Persistência } \\
\text { Respondedores a placebo } \\
\text { Não respondedores a placebo }\end{array}$ & $\begin{array}{l}4,69 \pm 0,44 \\
4,37 \pm 0,27\end{array}$ & 0,54 \\
\hline $\begin{array}{l}\text { AD - Autodirecionamento } \\
\text { Respondedores a placebo } \\
\text { Não respondedores a placebo }\end{array}$ & $\begin{array}{l}31,19 \pm 2,01 \\
32,41 \pm 1,24\end{array}$ & 0,60 \\
\hline $\begin{array}{l}\text { C-Cooperatividade } \\
\text { Respondedores a placebo } \\
\text { Não respondedores a placebo }\end{array}$ & $\begin{array}{l}31,38 \pm 1,14 \\
31,59 \pm 0,74\end{array}$ & 0,88 \\
\hline $\begin{array}{l}\text { AT - Autotranscendência } \\
\text { Respondedores a placebo } \\
\text { Não respondedores a placebo }\end{array}$ & $\begin{array}{l}16,69 \pm 1,18 \\
11,39 \pm 0,95\end{array}$ & $0,007^{*}$ \\
\hline
\end{tabular}

* Estatisticamente significado com $p \leq 0,05$ (teste $t$ ) 


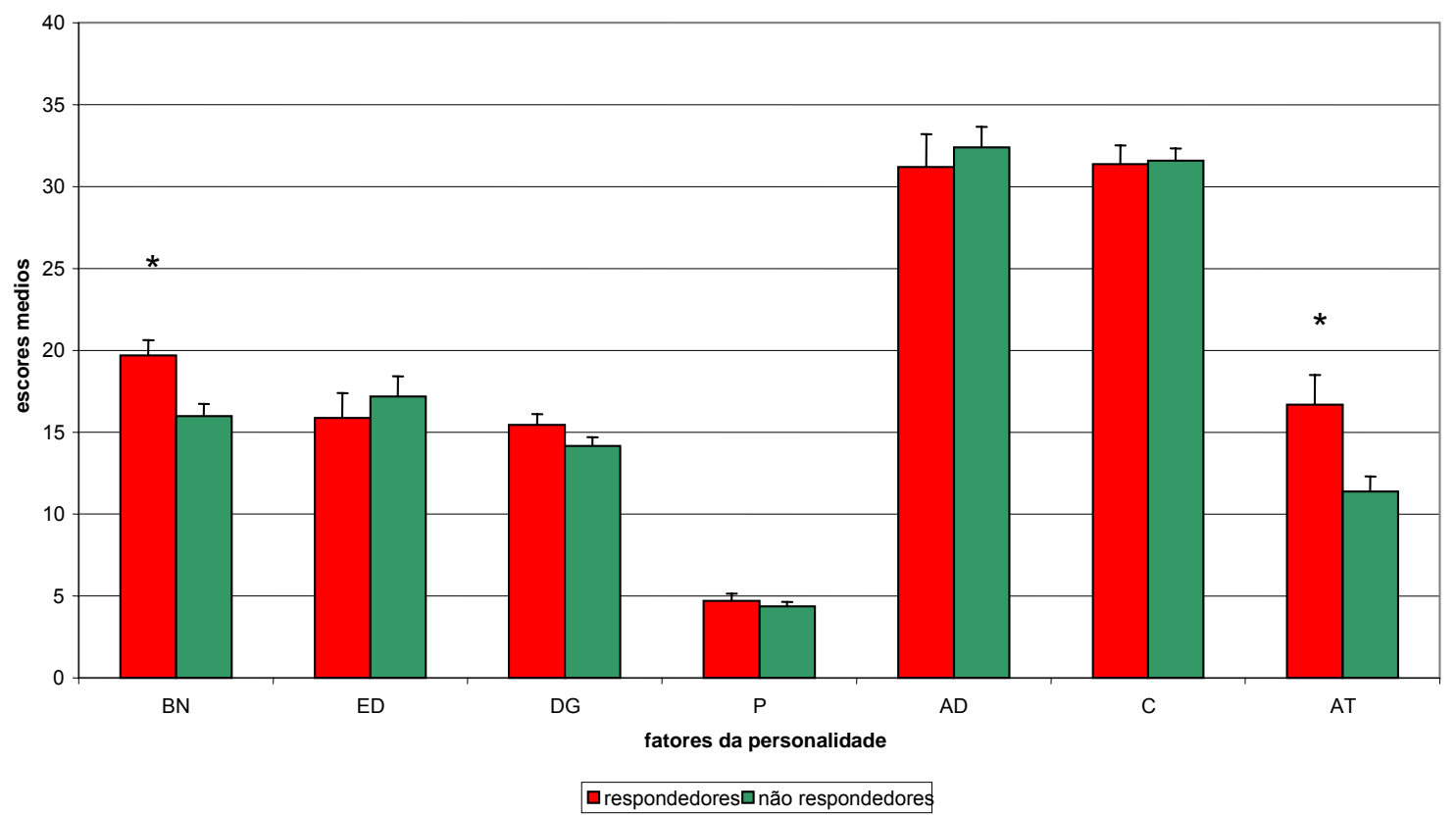

Figura 2 - Escores médios no Inventário de Temperamento e Caráter dos respondedores $(n=16)$ e não respondedores $(n=41)$ a placebo agrupando-se todos os sujeitos do estudo

$\left(^{*}\right)$ Estatisticamente significativo $(p<0,05)$ após ANOVA e análise de regressão multivariada. 
Tabela 8 - Resultados significativos da regressão multivariada considerando as variáveis idade, gênero, escolaridade e diagnóstico dos fatores de personalidade da amostra total com todos os sujeitos incluídos (Sujeitos normais, pacientes deprimidos e pacientes fóbicos) $(n=57)$

\begin{tabular}{|c|c|c|c|c|c|}
\hline Dimensões de Personalidade & Média \pm EPM & $\begin{array}{l}\text { ODDS } \\
\text { RATIO }\end{array}$ & $\begin{array}{c}\text { Intervalo } \\
\text { de } \\
\text { confiança }\end{array}$ & $P^{*}$ & $\mathbf{p}$ \\
\hline $\begin{array}{l}\text { BN - Busca de novidade } \\
\text { Respondedores a placebo } \\
\text { Não respondedores a placebo }\end{array}$ & $\begin{array}{r}19,69 \pm 0,94 \\
15,98 \pm 0,74\end{array}$ & 1,16 & $1,00-1,35$ & 0,040 & $0,007^{*}$ \\
\hline $\begin{array}{l}\text { AT - Autotranscendência } \\
\text { Respondedores a placebo } \\
\text { Não respondedores a placebo }\end{array}$ & $\begin{array}{l}16,69 \pm 1,18 \\
11,39 \pm 0,95\end{array}$ & 1,35 & $1,00-1,22$ & 0,050 & $0,007^{*}$ \\
\hline
\end{tabular}

$\mathbf{p}^{*}=$ QUI QUADRADO DE WALD

$\left({ }^{*}\right)$ Estatisticamente significativo $(p<0,05)$

$p=$ ANOVA 


\subsection{Variáveis genéticas}

A análise das variáveis genéticas foi realizada apenas nos voluntários que participaram da pesquisa em sujeitos normais. Dois voluntários não coletaram sangue e foram excluídos. Portanto, foram incluídos 19 sujeitos, sendo que 6 sujeitos responderam a placebo e 13 não responderam.

A tabela 9 apresenta a comparação das características sócio-demográficas dos respondedores e não respondedores a placebo dos sujeitos normais. Não houve diferenças estatisticamente significativa entre os grupos, de acordo com a resposta a placebo, em relação à idade $(p=0,06)$, escolaridade $(p=0,63)$ e sexo $(p=0,76)$.

Tabela 9 - Comparação das características sócio-demográficas entre os respondedores a placebo e os não respondedores na amostra de sujeitos normais $(n=19)$

\begin{tabular}{c|c|c|c}
\hline Características & $\begin{array}{c}\text { Nespondedores a } \\
\text { placebo (6) }\end{array}$ & $\begin{array}{c}\text { Não } \\
\text { respondedores } \\
\text { a placebo (13) }\end{array}$ & $\begin{array}{c}\mathbf{p} \\
\text { (teste t) }\end{array}$ \\
\hline $\begin{array}{c}\text { Idade } \\
\text { (Média } \pm \text { desvio padrão) }\end{array}$ & $42,50 \pm 6,22$ & $34,92 \pm 7,79$ & 0,06 \\
\hline $\begin{array}{c}\text { Escolaridade } \\
\text { (Média } \pm \text { desvio padrão) }\end{array}$ & $10,67 \pm 1,75$ & $11,15 \pm 2,12$ & 0,63 \\
\hline Gênero & 1 & 3 & 0,76 \\
Sexo masculino & 5 & 10 & \\
\hline Sexo feminino & 5 & & \\
\hline
\end{tabular}

As tabelas 10 a 13 apresentam a análise de associação entre os polimorfismos estudados e a resposta a placebo.

As figuras de 3 a 6 apresentam a distribuição do genótipo entre os respondedores e não respondedores a placebo.

A amostra estudada não tem poder adequado para detectar a associação de polimorfismos mantendo um alfa de $5 \%$. Portanto, a associação entre a resposta a placebo e variáveis genéticas tem caráter exploratório. Os resultados encontrados 
mostram associação entre polimorfismos, o polimorfismo 5HTTLPR com a resposta a placebo (tabela 10). Os resultados da associação entre a resposta a placebo e o polimorfismo 5HT1B (G681C), mostraram que existe uma tendência de associação com o alelo $G(p=0,06$ - tabela 11$)$.

A freqüência esperada para o alelo T do polimorfismo 5HT2A (C516T) é de 0,01\%. Devido ao tamanho de nossa amostra, não foi observada a presença desse alelo, o que impossibilita a realização da comparação entre sujeitos respondedores e não respondedores a placebo.

Tabela 10 - Análise de associação do polimorfismo 5HTTLPR em 6 sujeitos respondedores e 13 não respondedores a placebo

Teste de Associação Alélica

\begin{tabular}{c|c|c|c|c|c}
\hline Alelos & $\begin{array}{c}\text { Frequência em } \\
\text { Respondedores } \\
n(\%)\end{array}$ & $\begin{array}{c}\text { Frequência em Não } \\
\text { Respondedores } \\
n(\%)\end{array}$ & $\begin{array}{c}\text { Odds Ratio } \\
(I C ~ 95 \%)\end{array}$ & $X^{2}$ & $p$ \\
\hline Alelo L $\$$ & $4(33 \%)$ & $16(66 \%)$ & 1 & 2,93 & 0,09 \\
\hline Alelo S & $8(66 \%)$ & $8(33 \%)$ & $\begin{array}{c}0,25 \\
(0,05-1,08)\end{array}$ & & \\
\hline
\end{tabular}

Teste de Associação Genotípica

\begin{tabular}{l|c|c|c|c|c}
\hline Genótipos & $\begin{array}{c}\text { Frequência em } \\
\text { Respondedores } \\
n(\%)\end{array}$ & $\begin{array}{c}\text { Frequência em Não } \\
\text { Respondedores } \\
n(\%)\end{array}$ & $\begin{array}{c}\text { Odds Ratio } \\
(I C ~ 95 \%)\end{array}$ & $X^{2}$ & $p$ \\
\hline L/L & $1(17 \%)$ & $5(42 \%)$ & 1 & 1,5 & 0,22 \\
\hline L/S & $2(33 \%)$ & $6(50 \%)$ & $\begin{array}{c}0,6 \\
(0,04-8,73)\end{array}$ & 0,56 & 0,46 \\
\hline S/S & $3(50 \%)$ & $1(8 \%)$ & $\begin{array}{c}0,06 \\
(0,002-1,50)\end{array}$ & 3,84 & 0,05 \\
\hline
\end{tabular}




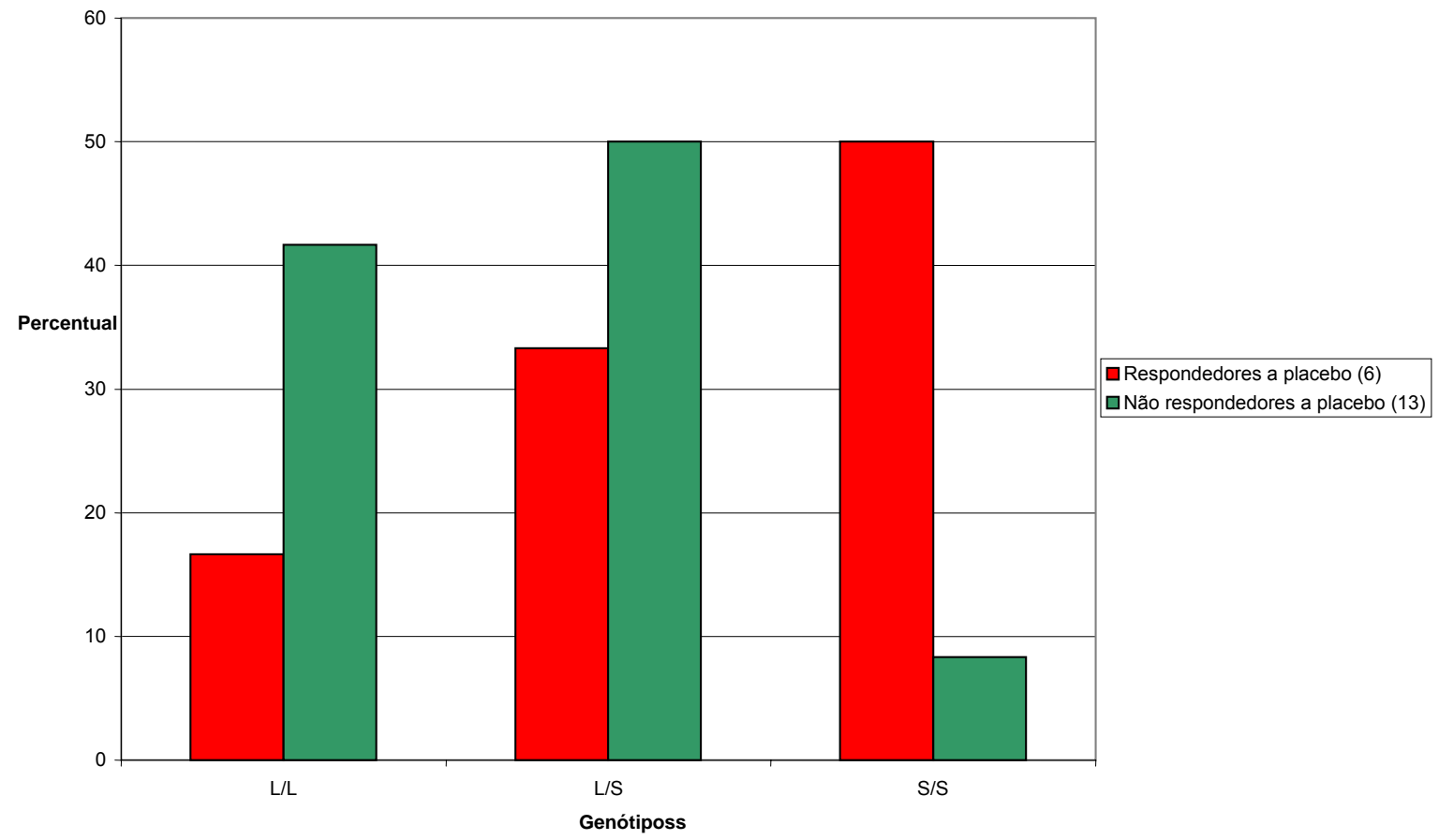

Figura 3 - Análise da distribuição dos genótipos L/L, L/S e S/S do 5HTTLPR (SLC6A4) entre os respondedores e não respondedores a placebo 
Tabela 11 - Análise de associação do polimorfismo 5HT1B (G861C) em 6 sujeitos respondedores e 13 sujeitos não respondedores a placebo

Teste de Associação Alélica

\begin{tabular}{|c|c|c|c|c|c|}
\hline Alelos & $\begin{array}{c}\text { Frequência em } \\
\text { Respondedores } \\
\text { n (\%) }\end{array}$ & $\begin{array}{c}\text { Frequência em } \\
\text { Não } \\
\text { Respondedores } \\
\text { n (\%) }\end{array}$ & $\begin{array}{l}\text { Odds Ratio } \\
\text { (IC 95\%) }\end{array}$ & $x^{2}$ & $p$ \\
\hline Alelo G § & $10(83 \%)$ & $14(54 \%)$ & 1 & \multirow[t]{2}{*}{4,27} & \multirow[t]{2}{*}{0,04} \\
\hline Alelo C & $2(17 \%)$ & $12(46 \%)$ & $\begin{array}{c}4,28 \\
(0,78-23,52)\end{array}$ & & \\
\hline
\end{tabular}

Teste de Associação Genotípica

\begin{tabular}{l|c|c|c|c|c}
\hline \multicolumn{1}{c|}{ Genótipos } & $\begin{array}{c}\text { Frequência em } \\
\text { Respondedores } \\
n(\%)\end{array}$ & $\begin{array}{c}\text { Frequência em } \\
\text { Não } \\
\text { Respondedores } \\
n(\%)\end{array}$ & $\begin{array}{c}\text { Odds Ratio } \\
(\text { IC 95\%) }\end{array}$ & $X^{2}$ & $p$ \\
\hline G/G & $4(67 \%)$ & $2(15 \%)$ & 1 & 4.33 & 0.03 \\
\hline G/C & $2(34 \%)$ & $10(77 \%)$ & 10 & 3.46 & 0.06 \\
\hline C/C & 0 & $1(8 \%)$ & - & - & - \\
\hline
\end{tabular}




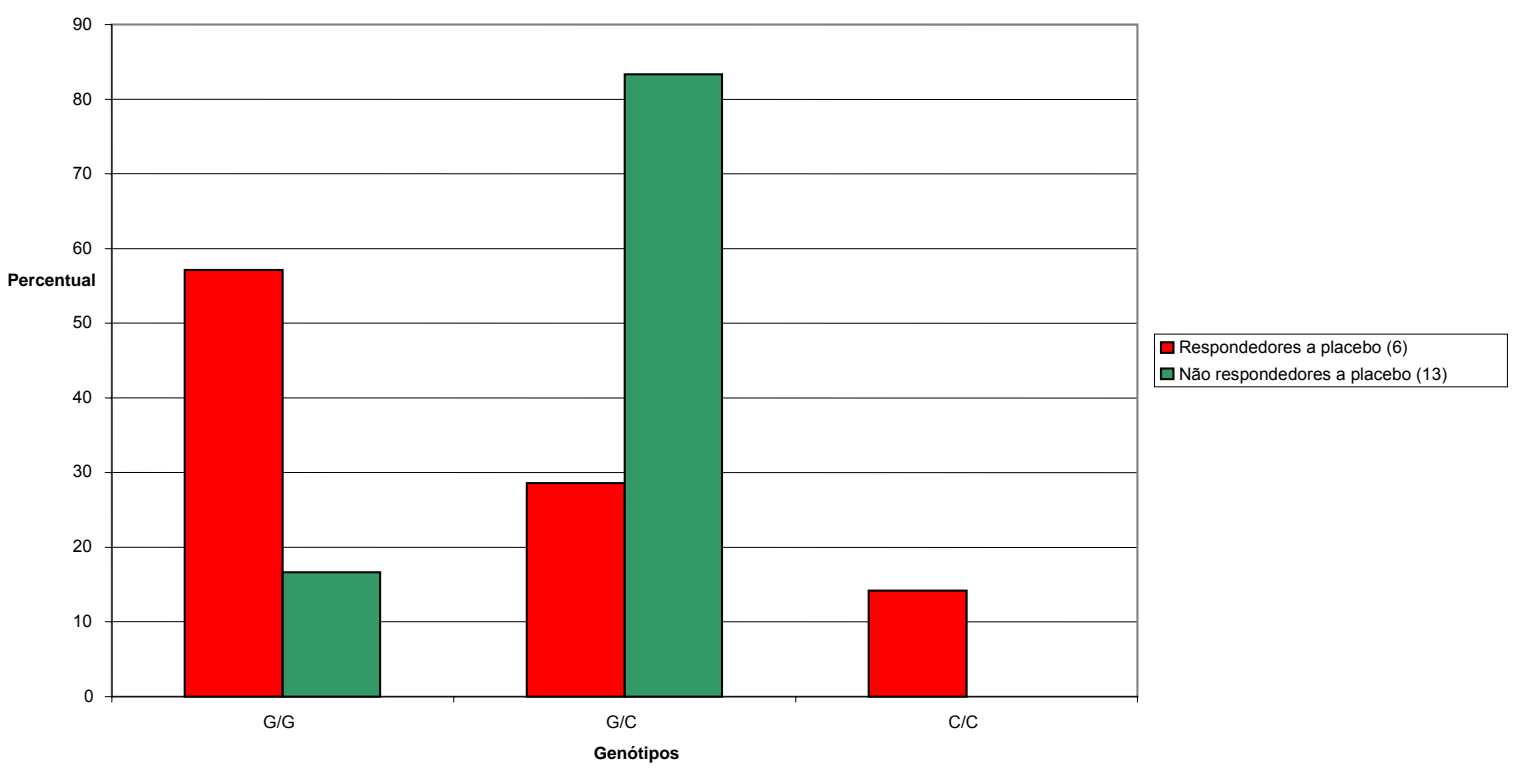

Figura 4 - Análise da distribuição dos genótipos G/G, G/C e C/C do gene do Receptor de Serotonina Subtipo 1B entre os respondedores e não respondedores a placebo 
Tabela 12 - Análise de associação do polimorfismo 5HT2A (T102C) em 6 sujeitos respondedores e 13 sujeitos não respondedores a placebo

\section{Teste de Associação Alélica}

\begin{tabular}{l|c|c|c|c|c}
\hline \multicolumn{1}{c|}{ Alelos } & $\begin{array}{c}\text { Frequência em } \\
\text { Respondedores }\end{array}$ & $\begin{array}{c}\text { Frequência em } \\
\text { Não } \\
\text { Respondedores }\end{array}$ & $\begin{array}{c}\text { Odds Ratio } \\
(\text { IC 95\%) }\end{array}$ & $X^{2}$ & $p$ \\
\cline { 1 - 4 } & $4(\%)$ & $14(54 \%)$ & 1 & 1,97 & 0,16 \\
\cline { 1 - 4 } Alelo T § & $8(66 \%)$ & $12(46 \%)$ & $\begin{array}{c}0,42 \\
(0,1-1,78)\end{array}$ & & \\
\hline
\end{tabular}

Teste de Associação Genotípica

\begin{tabular}{l|c|c|c|c|c}
\hline \multicolumn{1}{c|}{ Genótipos } & $\begin{array}{c}\text { Frequência em } \\
\text { Respondedores } \\
n(\%)\end{array}$ & $\begin{array}{c}\text { Frequência em } \\
\text { Não } \\
\text { Respondedores } \\
n(\%)\end{array}$ & $\begin{array}{c}\text { Odds Ratio } \\
(I C ~ 95 \%)\end{array}$ & $X^{2}$ & $p$ \\
\hline T/T & 0 & $4(30 \%)$ & - & - & - \\
\hline T/C & $4(66 \%)$ & $6(46 \%)$ & 1 & 0,78 & 0,37 \\
\hline C/C & $2(33 \%)$ & $3(23 \%)$ & 1 & 0,21 & 0,64 \\
\hline
\end{tabular}




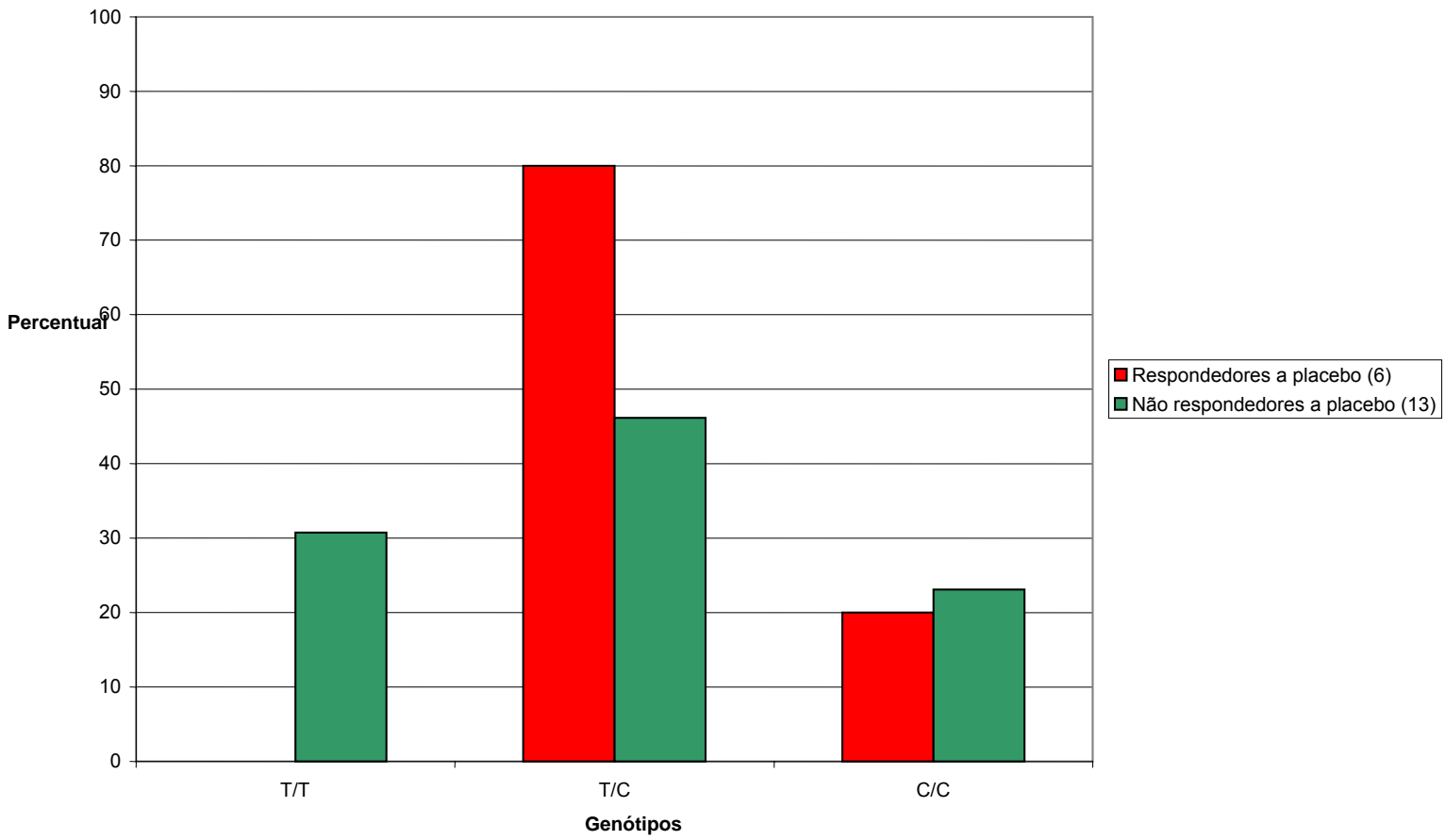

Figura 5 - Análise da distribuição dos genótipos T/T, T/C e C/C do gene HTR2A (T102C) entre os respondedores e não respondedores a placebo 


\section{DISCUSSÃO}

\subsection{Amostra}

A amostra utilizada neste estudo foi inferior a inicialmente prevista devido a grande dificuldade em encontrar estudos clínicos envolvendo antidepressivos e controlados com placebo. Isso provavelmente ocorreu devido à dificuldade em conseguir aprovação dos comitês de ética e da Conep da inclusão de placebo em pesquisas com novos psicofármacos.

Outra grande dificuldade foi a de localizar os sujeitos que haviam participado, visto que muitos telefones e endereços não estavam atualizados nos prontuários desses pacientes.

As características sócio-demográficas dos sujeitos respondedores não foram significativamente diferentes das dos não respondedores a placebo. Pud et al. (2006) observaram que as mulheres responderam significativamente mais a placebo que homens em um estudo com morfina. Moertel et al. (1976) descrevem que sujeitos mais inteligentes e com maior nível de escolaridade são mais propensos a responder a placebo. Analisando alguns trabalhos que associavam a resposta placebo à escolaridade, Thompson (2005) observou que os resultados encontrados eram inconsistentes.

\subsection{Características de Personalidade de sujeitos normais e pacientes psiquiátricos}

No presente estudo, observou-se que os escores médios dos fatores de personalidade esquiva ao dano e autodirecionamento foram, respectivamente, maiores e menores que dos sujeitos normais. Os pacientes deprimidos também apresentaram escores mais elevados no fator de personalidade autotranscendência (AT) quando comparados com sujeitos normais e pacientes fóbicos. Os sujeitos normais apresentaram escores significativamente mais elevados que os pacientes fóbicos no fator de personalidade cooperatividade.

As diferenças em determinados traços de personalidade entre sujeitos normais e pacientes psiquiátricos são muito estudadas e freqüentemente descritas (Cloninger et al., 1993, 1998, 2006; Jylha et al., 2005; Farmer et al., 2003; Lochner 
et al., 2007). Alguns estudos sugerem que fatores de personalidade podem estar estar envolvidos no próprio desenvolvimento de sintomas depressivos (Farmer et al., 2003; Grucza et al., 2002; Pekka et al., 2005) ou de transtornos de ansiedade (Lochner et al., 2007).

A associação entre personalidade e doenças psiquiátricas é embasada nas teorias que tentam explicar os mecanismos fisiológicos subjacentes aos transtornos psiquiátricos e no modelo psicobiológico de temperamento e caráter proposto por Cloninger (1987). Para Cloninger et al. (1987), as características de temperamento, busca de novidade, esquiva ao dano e dependência de gratificação, são herdadas e estão relacionadas, respectivamente, com os sistemas de neuromediadores dopamininérgicos, serotonérgicos e noradrenérgicos, neuromediadores também envolvidos nos transtornos psiquiátricos.

Grucza et al. (2002) e Pekka et al. (2005) observaram que sujeitos deprimidos apresentaram escores médios mais elevados do fator de personalidade esquiva ao dano e escores menores do fator auto-direcionamento quando comparados com a população geral. Pacientes fóbicos, quando comparados com a população geral, apresentaram escores significativamente maiores do fator de personalidade esquiva ao dano e escores significativamente menores dos fatores busca de novidade e autodirecionamento (Lochner et al., 2007).

Os resultados encontrados no presente estudo são consistentes com os obtidos nos estudos acima citados.

\subsection{Características de personalidade e resposta a placebo}

A associação entre resposta a placebo e características de personalidade foi pouco estudada.Algumas pesquisas disponíveis sugerem que as características de personalidade podem influenciar tanto na resposta a placebo quanto na resposta ao fármaco (Hutchison et al., 1999; Natrielli, 2002; Raby et al., 2005; Pud et al., 2006; Geers et al., 2005). No entanto, de acordo com Hyland et al. (2007), os resultados que associam a resposta a placebo com variáveis de personalidade são inconsistentes porque não conseguiram ser replicados.

Os resultados do presente estudo mostraram a influência de variáveis de personalidade na resposta a placebo. Nos sujeitos normais, os respondedores a placebo apresentaram escores mais elevados que os não respondedores nos 
fatores de personalidade busca de novidade $(B N)$ e dependência de gratificação (DG). Nos pacientes deprimidos, os respondedores a placebo apresentaram escores mais elevados que os não respondedores no fator de personalidade autotranscendência. Nos pacientes fóbicos não foram encontrados resultados estatisticamente significativo em nenhum dos sete fatores de personalidade

O fator dependência de gratificação é caracterizado como uma tendência hereditária que o individuo tem em responder de maneira intensa a sinais de recompensa, visando à obtenção de prêmios. A norepinefrina (Cloninger. 1998; Guerra et al., 1999) e a dopamina (Guerra et al., 2000) são neurotransmissores provavelmente associados a esse fator de personalidade, enquanto que o sistema noradrenérgico parece associado ao fator busca de novidade (Guerra et al., 2000).

Os pacientes com diagnóstico de fobia social diferenciam-se dos sujeitos normais e dos pacientes deprimidos por apresentarem escores mais elevados no fator de personalidade esquiva ao dano (ED). Segundo Cloninger et al. (1987), este traço de personalidade envolve variações no sistema de comportamento inibitório, em que indivíduos com altos escores para ED tendem a responder intensamente a estímulos aversivos, com o objetivo de evitar punições e frustrações.

O fator de personalidade esquiva ao dano (ED) está associado à funcionalidade do sistema serotonérgico (Cloninger 1998). Alto escore em ED parece estar relacionado com um nível maior de liberação de serotonina da membrana pré-sináptica e com uma baixa regulação no receptor de serotonina póssináptico (Guerra et al., 2000). No entanto, as projeções serotonérgicas do núcleo dorsal da rafe para a substância negra inervam os neurônios que contém dopamina na substância negra compacta (SNc) e na área tegmentar ventral (ATV) influenciando a descarga de dopamina (Pliszka, 2004). Os neurônios serotonérgicos ao inibir os neurônios dopaminérgicos na via nigroestriatal tornam-se essenciais na inibição da atividade condicionada pelos sinais de recompensa e na frustração pela não obtenção de recompensa (Thiebot, et al., 1984, citado por Cloninger, 1987).

A conseqüência final desse processo, que conta ainda com a liberação de hormônios como o cortisol, pode ser uma redução na atividade exploratória do indivíduo (Kellel et al., 1984, citado por Cloninger, 1987).

Embora a análise das amostras individuais tenha mostrado que os fatores de personalidade busca de novidade, dependência de gratificação e autotranscendência discriminaram os respondedores dos não respondedores a 
placebo, nenhuma dessas variáveis foi determinante quando as sub-amostras foram analisadas conjuntamente.

$\mathrm{Na}$ amostra total $(n=57)$ a análise de regressão multivariada identificou entre as variáveis estudadas (sexo, idade, escolaridade, diagnóstico e fatores de personalidade) duas variáveis significativamente relacionadas à resposta a placebo: os fatores de personalidade busca de novidade (BN) e autotranscendência (AT).

O fator busca de novidade é classificado como uma dimensão do temperamento (herança genética) e autotranscendência (AT) como uma dimensão do caráter (influência ambiental).

Escores mais elevados em busca de novidade, observados nos respondedores a placebo, indicam uma tendência maior em apresentar atividades exploratórias frente a novos estímulos e a maior susceptibilidade à estimulação ambiental (Cloninger et al., 1993). Os indivíduos que apresentam essas características tendem a ser mais exploradores, extravagantes, desorganizados e também apresentam uma maior tendência a enfrentar desafios e a buscar recompensas (Cloninger et al., 1997).

Estudos anteriores mostraram que indivíduos com escores mais elevados em busca de novidade também apresentaram resposta mais positiva tanto ao tratamento farmacológico quanto ao placebo (Natrielli, 2002; Hutchison et al., 1999).

Cloninger et al. $(1987,1996)$ descreveram que o sistema dopaminérgico estaria associado ao fator de personalidade busca de novidade e que o comportamento exploratório espontâneo dependeria da integridade desse sistema. De la Fuente-Fernandez et al. (2004) observaram que o efeito placebo gerado pela expectativa de um benefício clínico ou de recompensa ativa a região estriado ventral do cérebro, que por sua vez irá liberar o neuromediador dopamina.

Uma das hipóteses mais relacionada ao efeito placebo é a expectativa em relação ao benefício clínico do tratamento (Geers et al., 2004; Jensen et al., 1991). A expectativa e o sistema de recompensa foram associados à atividade do neuromediador dopamina (De la Fuente-Fernandez et al., 2004). Essa associação entre efeito placebo, expectativa e dopamina poderia explicar, em parte, a característica de personalidade dos sujeitos que responderam a placebo no presente estudo. Os escores mais elevados no fator busca de novidade poderiam estar associados a níveis maiores de atividade dopaminérgica, que por sua vez estão associados aos mecanismos envolvidos na resposta a placebo. 
O grupo que respondeu a placebo também apresentou escore significativamente mais elevado no fator de personalidade autotranscendência (AT). De acordo com Cloninger et al. (1993), estes indivíduos tendem a ser mais susceptíveis a sugestões e a aceitar melhor as explicações espirituais do que as racionais. Eles também respondem de maneira mais exploratória ou extravagante aos estímulos ambientais. Sugestionabilidade e espiritualidade parecem favorecer a resposta a placebo, visto que, outros estudos demonstraram que sujeitos com essas características responderam mais intensamente a placebo (Hyland et al., 2007; Hyland et al., 2006; Petry et al., 2004; Fisher et al., 1997; Mc Cann et al., 1992). De acordo com Hyland et al. (2007), os indivíduos com escores mais elevados em autotranscendência são submissos e mais prováveis em concordar com a sugestão de um pesquisador.

A espiritualidade é uma das características dos indivíduos com escores mais elevados no fator AT e tem sido correlacionada com expectativa e otimismo (Hyland et al., 2007; Salsman et al., 2005), características também associadas à resposta a placebo (Hyland et al., 2007; Geers et al., 2004, 2005, 2007). De acordo com Petry et al. (2004), a espiritualidade funciona como um catalisador na cura de pacientes que procuram os tratamentos alternativos.

\subsection{Associação de Resposta Placebo a Polimorfismos de Genes do Sistema Serotonérgico}

A influência das variáveis genéticas é pouco estudada em relação à resposta placebo. Foram encontrados apenas dois estudos que associaram o polimorfismo 5HTTLPR no gene SLC6A4 e resposta a placebo em pesquisas com antidepressivos. Sakul et al. (2004) e Durham et al. (2003) observaram que no grupo de respondedores a placebo a freqüência de indivíduos homozigotos para o alelo longo (L/L) foi menor que a freqüência de indivíduos com alelo curto (S/S e L/S).

No presente estudo, a amostra para a determinação da influência das variáveis genéticas na resposta a placebo foi pequena $(n=19)$ e não teve o poder adequado para detectar a associação dos polimorfismos com a resposta a placebo mantendo um alfa de $5 \%$. Sendo assim, os resultados da associação entre as variáveis genotípicas e resposta a placebo podem ser considerados apenas de caráter exploratório. 
Os resultados sugeriram a associação do polimorfismo 5HTTLPR e uma tendência de associação do polimorfismo 5HTR1B (G861C) com resposta a placebo. Apesar das limitações de nossa amostra, a associação com o polimorfismo 5HTTLPR e resposta placebo foi também verificada por Sakul et al. (2004) e Durham et al. (2003).

O alelo curto (S) do 5HTTLPR promove diminuição da produção da proteína transportadora de serotonina - 5HTT (Lesch et al., 1996). É possível que essa menor eficiência de transcrição do alelo $S$ favoreça a resposta a placebo através de uma maior inibição do sistema dopaminérgico, ocasionada pelo aumento de disponibilidade de serotonina na fenda sináptica. Pode-se supor também que a diminuição na atividade dopaminérgica alteraria a sensibilidade do sistema de recompensa cerebral influenciando a resposta placebo.

O 5HTR1B (G861C) é pouco polimórfico, ou seja, o alelo C apresenta uma freqüência esperada baixa (aproximadamente 0,01\%). A tendência de associação aqui encontrada tem a sua interpretação limitada devido à ausência de homozigotos C/C. É possível que alelos raros estejam associados a alguns fenótipos, no entanto, esta hipótese precisaria ser testada em uma amostra com poder suficiente para detectar uma associação de pequeno efeito. 


\subsection{Limitações do estudo e considerações finais}

O placebo é uma importante ferramenta metodológica nas pesquisas com medicamentos e o entendimento dos mecanismos envolvidos na sua resposta ainda não é muito bem compreendido. Diversas variáveis podem estar envolvidas na resposta a placebo, como características de personalidade, fatores genéticos, neuromediadores cerebrais (dopamina, serotonina, adrenalina), contexto (postura do pesquisador ou médico e o ambiente da pesquisa), expectativa do tratamento e condicionamento anterior.

O presente estudo buscou identificar as características de personalidade e as variáveis genéticas de sujeitos sadios e pacientes psiquiátricos que responderam a placebo em ensaios clínicos com antidepressivos. O ambiente ou contexto em que os ensaios foram realizados e a expectativa dos sujeitos em relação ao tratamento não foram analisados, o que pode limitar os presentes resultados.

Apesar da amostra total utilizada para a análise de personalidade ter sido bastante heterogênea (sujeitos normais e pacientes com deferentes diagnósticos psiquiátricos e gravidade) a análise de regressão mostrou que dois fatores de personalidade foram associados à resposta placebo.

A amostra utilizada para a análise das variáveis genéticas foi pequena, o que limitou a interpretação dos resultados. Do ponto de vista fenotípico, no entanto, esta amostragem foi bastante homogênea, composta por sujeitos sem diagnóstico psiquiátrico e sem histórico familiar de transtornos mentais.

Nossos resultados sugerem que a inclusão de sujeitos com altos escores em busca de novidade, autotranscendência e dependência de gratificação em ensaios clínicos poderiam criar um viés amostral, visto que estes indivíduos seriam mais susceptíveis ao efeito placebo.

Outro fator importante que deve ser considerado na análise da influência de variáveis genotípicas na resposta a placebo é que características individuais, como personalidade, não são determinadas por um único gene. Diante disso é necessária a utilização de um número maior de marcadores genéticos em diferentes genes. 


\section{CONCLUSÕES}

- A freqüência de sujeitos que respondeu a placebo na amostra total e nas individuais (pacientes fóbicos e deprimidos e sujeitos sadios) foi de aproximadamente $30 \%$.

- Os sujeitos que responderam a placebo apresentaram escores mais elevados para os fatores de personalidade busca de novidade (BN) e autotranscendência (AT) quando comparados aos não respondedores na amostra total $(n=57)$.

- A análise das variáveis genotípicas teve caráter apenas exploratório, no entanto, os resultados obtidos nos sujeitos sadios sugerem a associação da freqüência alelo curto (S) do polimorfismo 5HTTLPR com resposta placebo. 


\section{REFERÊNCIAS BIBLIOGRÁFICAS}

American Medical Association. World Medical Association Declaration of Helsinki: recommendation guiding physicians in biomedical research involving human subjects. The journal of the American Medical association. 1997; 10: 925-926.

American pain Society. Position statement.on the use of placebos in pain management. The Journal of Pain. 2005; 6: 215-217.

American Psychiatric Association: Diagnóstic and Statistical Manual of Mental Disorders. 4. ed., Washington, DC: American Psychiatric Association; 1994.

Balint M. The doctor, the patient and the illness. Pitman Medical Publishing. 1957; 18.

Barsky AJ, Saintfort R, Rogers MP, Borus JF. Nonspecific medication side effects and the nocebo phenomenon. American Medical Association. 2002; 287:622-627.

Beecher HK. The powerfull placebo. JAMA. 1955; 159: 1602-1606.

Benedetti F. How the doctor's words affect the patient's brain. Evaluation \& The Health Professions. 2002; 25:369-386.

Benedetti F. Mechanism of placebo and placebo-related effects across diseases and treatments. Annual Review of Pharmacology and Toxicology. 2008; 48:33-60.

Benedetti F, Mayberg HS, Wager T.D, Stohler CS, Zubieta JK. Neurobiological Mechanism of the placebo effect. The Journal of neuroscience. 2005; 25:1039010402.

Benedetti F, Pollo A, Lopiano L, Lanotte M, Vighetti S, Innocenzo R. Conscious expectation and unconscious conditioning in analgesic, motor, and hormonal placebo/nocebo responses. The Journal of Neuroscience. 2003; 10:4315-4323.

Benedetti F, Pollo A, Lopiano L, Vighetti S, Rainero I. Conscious Expectation and unconscious conditioning in analgesic, motor, and hormonal placebo/nocebo responses. The Journal of Neuroscience. 2003; 23:4323-4315.

Benson $\mathrm{H}$. The nocebo effect: hiatory and physiology. Preventive medicine. 1997; 26 : 612-615.

Branithwaite A, Cooper P. Analgesic effects of branding in treatment of headaches. British Medical Journal. 1981; 282: 1576-1578.

Brown WA. The best medicine. Psychology Today Magazine. 1997. 
Caen AJM, Kaptchuk TJ, Tijssen JGP, Kleijnen J. Placebos and placebo effect in medicine: historical overview. Journal of Royal Societ of Medicine. 1999; 92: 511515.

Carvalho CC. Do poder das palavras às palavras do poder. Revista Portuguesa de Psissomática. 2004;6:55-62.

Cloninger CR. A systematic method for clnical description and classification of personality variants. A proposal. Archives General Psychiatry. 1987; 44: 573588.

Cloninger CR, Svrakic, DM, Przybeck TR. Can personality assessment predict future depression? A twelve-month follow-up of 631 subjects. Journal of Affective Disorders. 2006; 92: 35-44.

Cloninger CR. A unified biosocial theory of personality and its role in the development of anxiety states. Psychiatric Developments. 1986; 3: 176-226.

Cloninger CR. Neurogenetic adaptative mechanisms in alcoholism. (genetic, social factors in alcoholism). Science. 1987; 410: 7.

Cloninger CR. Spirituality and the science of feeling good. (Special section: Spirituality/Medicine Interface Project). Southern Medical Journal. 2007; 700:4.

Cloninger CR. The science of well-being: an integrated approach to mental health and its disorders. Special Article Department of Psychiatric, Washington University School of medicine, 2006.

Cloninger CR, Adolfsson R, Svrakic DM. Mapping genes for human personality. Nature Genetics. 1996; 12.

Cloninger CR, Bayon C, Svrakic DM. Measurement of temperament and character in mood: a model of fundamental states as personality types. Jornal of Affective Disorders. 1998; 51: 21-32.

Cloninger CR, Svrakic DM, Przybeck TR. A psychobiological model of temperament and character. Archives of General Psychiatry. 1993; 50: 975-90.

De la Fuente-Fernandez R, Stoessl AJ. The biochemical bases for reward implications for placebo effect. Evaluation \& the Health Professions. 2002; 25: 387398.

De la Fuente-Fernandez R, Stoessl AJ. The placebo effect in neurological disorders. The Lancet Neurology. 2002; 1: 85-91.

De la Fuente-Fernandez R, Schulzer M, Stoessl AJ. Placebo mechanism and reward circuitry: Clues from Parkinson's diseases. Biological Psychiatric. 2004; 56:67-71.

De la Fuente-Fernandez R. Uncovering the hidden placebo effect in deep-brain stimulation for Parkinson's disease. Parkinsonism and Related Disorders. 2004; 10:125-127. 
Durham LK, Webb SM, Milos PM, Clary CM, Seymour AB. The serotonin transporter polymorphism, 5HTTLPR, is associated with a faster response time in an elderly population with major depressive disorder. Psychopharmacology. 2004; 174: 525529.

Eccles R. Mechanism of the placebo effect of sweet cough syrups. Respiratory Physiology \& Neurobiology. 2006; 152:340-348.

Evans RW, Rogers MP. Headaches and the nocebo effects. Headache. 2003; 42: 1113-1115.

Farmer A, Mahmood A, Redman K, Harris T, Stephanie S, McGuffin P. A sib-pair study of the temperament and character inventory scales in major depression. Archives of General Psychiatry. 2003; 60:490-496.

Fuentes D, Tavares H, Camargo CHP, Gorenstein C. Inventário de Temperamento de Caráter de Cloninger - Validação da Versão em Português. Gorenstein C, Andrade LHSG, Zuardi AW. Escalas de avaliação clínica em psiquiatria e psicofarmacologia. Lemos Editorial; 1999. Vol. 25, p. 363-376.

Geers AL, Helfer SG, Weiland PE, Kosbab K. Expectations and placebo response. A laboratory investigation into the role of somatic focus. Journal of Behavioral Medicine. 2006. 29:171-178.

Geers AL, Kosbab K, Helfer SG, Weiland PE, Wellman JA. Further evidence for individual differences in placebo responding: An interactionist perspective. Journal of Psychosomatic Research. 2007; 62:563-570.

Geers AL, Weiland PE, Kosbab K, Helfer SG. Goal activation, expectation, and placebo effect. Journal of Personality and Social Psychology. 2005; 2:143-159.

Geers AL, Weiland PE, Kosbab K, Landry SJ. Goal activation, and the placebo effect. Journal of Personality and Social Phycology. 2005; 89:143-159.

Geers LA, Helfer GH, Kosbab K, Weiland PE, Landry SJ. Reconsidering the role of personality in placebo effects: Dispositional optimism, situacional expectation, and the placebo response. Journal of Psychosomatic. 2004; 58: 121-127.

Gentil V, Lobo DSS, Henna E, Zilberman M, Gorenstein C. Personality profile predicting placebo in psychiatrically normal volunteers. Journal Psychopharmacology. 2004, 18 (supl. 3): A19.

Gorenstein C, Henna E, Lobo D, Zilberman M, Gentil V. Placebo effect in psychiatrically normal volunteers. International Journal of Neuropsychopharmacology. 2004; 7 (supl.1): S451.

Grucza RA, Przybeck TR, Spitznagel EL, Cloninger CR. Personality and depressive symptoms: a multi-dimension analysis. Journal of Affective Disorders. 2003; 74: 123130. 
Guerra G, Zaimovic A, Timpano M, Zambelli U, Delsignore R, Brambilla F. Neuroendocrine correlates of temperamental traits in humans. Psychoneuroendocrinology. 2000; 25: 479-496.

Hagihara A, Tarumi K. Doctor and patient perception of the level of doctor explanation and quality of patient-doctor communication. Scand Journal Caring. 2006; 20:143-150.

Ham BJ, Him YH, Choi MJ, Cha JH, Choi YK, Lee MS. Serotonergic genes and personality traits in the Korea population. Neuroscience Letter. 2004; 354: 2-5.

Heils A, Teufel A, Petri S, Strober G, Riederer P, Bengel D, Lesch P. Allelic variation of human serotonin transporter gene expression. Journal Neurochemical. 1996; 66: 2621-2624.

Herzhaft G. The nocebo effect. Encephale. 1969; 58: 486-503.

Hulley, SB. e Cummings SR. Designing Clinical Research 1988, Baltimore: Williams e Wilkins, p 219.

Hutchison KE, Wood MD, Swift R. Personality factors moderate subjective and psychophysiological response to d-amphetamine in humans. Experimental and Clinical Psychopharmacology. 1999; 7:493-501.

Hyland ME, Geraghty AWA, Joy OET, Turner SI. Spirituality predicts outome independently of expectancy following flower essence self-treatment. Journal of Psychosomatic Research. 2006; 60: 53-58.

Hyland ME, Geraghty AWA, Whalley B. Dispositional predictors of placebo responding: a motivacional interpretation of flower essence and gratitude therapy. Journal of Psychosomatic Research. 2007; 62: 331-340.

Jensen MP, Karoly P. Motivation and expectancy factors in symptom perception: a laboratory study of the placebo effect. Psychosomatic Medicine. 1991; 53:144-152.

Jonsson EG, Cichon S, Gustavsson JP, Grunhage F, Forslund K, Mattila-Evenden M, Rylander G, Asberg M, Farde L, Propping P, Nothen MM. Association between a promoter dopamine D2 receptor gene variant and the personality trait detachment. Biological Psychiatry. 2003 1;53(7):577-84.

Jylha P, Isometsa E. Temperament, character and symptoms of anxiety and depression in the general population. European Psychiatry. 2006; 21:389-395.

Kirsch I, Weixel LJ. Double-Blind versus deceptive administration of a placebo. Behavioral Neuroscience. 1988; 102: 319-323.

Kloaterhalfen S, Enck P. Psychobiology of the placebo response. Autonomic Neuroscience: Basic and Clinical. 2006; 125:94-99. 
Koshi EB, Short CA. Placebo theory and its implications for research and clinical practice: a review of the recent literature. Pain Practice. 2007; 7:4-20.

Krell VH, Leuchter FA, Morgan M, Cook IA, Abrams RN. Subject expectation of treatment effectiveness and outcome of treatment with an experimental antidepressant. Journal Clinical Psychiatry. 2004; 65: 1174-1179.

Lachman HM, Papolos DF, Saito T, Yu YM, Szumlanski CL, Weinshilboum RM. Human catechol-O-methyltransferase pharmacogenetics: description of a functional polymorphism and its potential application to neuropsychiatric disorders. Pharmacogenetics. 1996; 6: 243-250.

Lahuerta J, Rivas EG, Frias J, Gracia D, Dal-Ré R. Controvérsias éticas sobre la utilización de placebo como tratamiento control em los ensayos clínicos en neurologia. Neurologia. 2007; 22:106-113.

Lesch KP, Bengel D, Heils A, Sabol S, Greenberg B, Petri S, Benjamin J, Mulher C, Hamer D, Murphy D. Association of anxiety-related traits with a polymorphism the in serotonin transporter gene regulatory region. Science. 1996; 274: 1527-1530.

Lidstone SC, StoessI JAJ. Understanding the placebo effect: contribution from neuroimaging. Molecular Imaging and Biological. 2007; 9: 176-185.

Lochner C, Hemmings SS, Kinnear C, Schoeman R, Annerbrink K, Olsson M, Eriksson E, Moolman-Smook J, Allgulander C, Stein DJ. Genetics and personality traits in patients with social anxiety disorder: A case-control study in South Africa. European Neuropsychopharmacology. 2007; 17: 321-327.

Macedo A, Farré M, Baños JE. A meta-analysis of the placebo response in acute migraine and how this response may be influenced by some of the characteristics fo clinical trials. European Journal of Clinical Pharmacology. 2006; 62: 161-172.

Macedo A, Farre M, Barros JE. Placebo effect and Placebo. What are we talking about? Some conceptual and historical considerations. European Journal of Clinical Pharmacology. 2003; 59: 337-342.

MacMahon FJ, Buervenich S, Charney D, Kipsky R, Rush AJ, Wilson AF, Sorant AJM, Papanicolaou GJ, Laje G, Madhukar HT, Wisniewski SR, Manjii H. The American Journal of Human Genetics. 2006; 78:804-814.

Mayberg HS, Silva JA, Brannan SK, Tekell JL, Mahurin RK, McGinnis S, Jerabek, PA. The functional neuroanatomy of the placebo effect. American Journal of Psychiatry. 2002; 159: 728-737.

McCann CC, Goldfarb B, Frisk M, Quera-Salva MA, Meyer P. The role of personality factors and suggestion in placebo effect during mental stress test. Journal Clinical Pharmacology. 1992; 33: 107-110.

Miller SA, Polesky HF. A single salting out procedure for extracting DNA from human nucleated cells. Nucleic Acids Res. 1988; 16: 1215. 
Moerman DE, Jonas WB. Deconstructing the placebo effect and finding the meaning response. Annals of Internal Medicine. 2002; 136:471-476.

Moeman DE. The meaning response: thinking about placebos. Pain Practice. 2006; 6: 233-236.

National Institute of Health. Regulations and Ethical Guidelines (http://ohsr.od.nih.gov); 2004.

Natrielli DGF. Neurobiologia da personalidade. Temas e Prática do Psiquiatra. 2002; 32:1-152.

Noblett, KL, Coccaro EF. Molecular genetics of personality. Current Psychiatry Report. 2005; 1: 73-80.

Oosterbaan DB, Van Balkom AJLM, Spinhoven P, Van Dyck R. The placebo response in social phobia. Journal Psychopharmacology. 2001; 15:199.

Pacheco-Lopez G, Engler H, Niemi MB, Schedlowski M. Brain, Behavior, and Immunity. 2006; 20:430-446

Pekka J, Isometsa E. Temperament, character and symptoms of anxiety and depression in the general population. European Psychiatric. 2006; 21: 389-395.

Perlis ML, Jungquist CR, Pigeon WR, Matteson SE. Placebo effects in primary insomnia. Sleep Medicine Review. 2005; 9:381-389.

Petrovic P, Kalso E, Peterson KM, Ingar, M. Placebo and opioid analgesia-imaging a shared neuronal network. Science. 2002; 295: 1737-1740.

Petry JJ, Finkel R. Spirituality and choice of health care practitioner. The Journal of Alternative and Complementary Medicine. 2004; 6: 939-945.

Pud D, Yarnitsky D, Sprecher E, Rogowski Z, Adler R, Eisenberg E. Can personality traits and gender predict the response to morphine? An experimental cold pain study. European Journal of Pain. 2006. 10:103-112.

Purcell S, Cherny SS, Sham PC. Design of linkage and association genetic mapping studies of complex traits. Genetic Power Calculator, 2003. Bioinformatics; 19:149150.

Quilty LC, Fruyt F, Rolland JP, Kennedy SH, Rouillon F, Babgy RM. Dimensional personality traits and treatment outcome in patients with major depressive disorder. Journal of Affective Disorders. 2007 - in press.

Raby WN, Carpenter KM, Aharonovich E, Rubin E, Bisaga A, Levin F, Nunes EV. Temperament Characteristics by the tridimensional personality questionnaire, moderate the response to sertraline in depressed opiate-dependent methadone patients. Drug Alcohol Dependence. 2006; 81: 283-292. 
Rajagopal S. The placebo effect. Psychiatric Bulletin. 2006; 30:185-188.

Ray J, Hansen S, Waters N. Links between temperamental dimension and brain monoamines. Behavioral Neuroscience. 2006; 120:85-92.

Reeves RR, Ladner M.E, Hart RH, Burke RS. Nocebo effects with antidepressant clinical drug trial placebos. General Hospital Psychiatry. 2007; 29: 275-277.

Sadock BJ, Sadock VA. Compêndio de Psiquiatria: Ciência do comportamento e psiquiatria Clínica. $9^{\circ}$ edição, ArtMed; 2007: p.168.

Sakul H. Pharmacogenomics and placebo response: results from recent major depression trials at Pfizer. Presented at $44^{\text {th }}$ Annual NCDEU( New Clinical Drug Evalution Unit) Meeting, Arizona Biltmore, Phoenix; 2004.

Samochowiec J, Syrek S, Michal P, Ryzewska WA, Samochowiec A, Horodnicki J, Zakrzewska M, Kucharska MJ. Polymorphism in the serotonin transporter and monoamine oxidase A genes and their relationship to personality traits measured by the temperament and character inventory and NEO five-factor inventory in healthy volunteer. Neuropsychobiology. 2004; 50:174-181.

Serreti A, Calati R, Giegling I, Hartmann AM, Moller HJ, Colombo C, Rujescu D. 5HT2a SNPs and the temperament and character inventory. Progress In NeuroPsychopharmacology \& Biological Psychiatric. 2007; 31: 1275-1281.

Shepherd M. The Placebo: from specificity to then non-specific and back. Psychological Medicine. 1993; 23: 569-578.

Smith papyrus-Eber papyrus. www.crystalinks.com/egyptmedicine.htma, [10 jan. 2002].

Svrakic DM, Whitehead C, Przybeck TR, Cloninger CR. Differential diagnosis of personality disorders by the seven-factor model of temperament and character. Archives of General Psychiatric. 1993; 50: 991-999.

Szekely A, Ronai Z, Nemoda Z, Kolmann G, Gervai J, Sasvari SM. Human personality dimension of persistence and harm avoidance associated with DRD4 and 5-HTTLPR polymorphism. American Journal of medical Genetics Part B: Neuropsychiatric Genetics. 2004; 126: 106-110.

Talley NJ, Locke GR, Lahr BD, Zinsmeister AR, D'Elias TV, Tack J, Earnest DL. Predictors of the placebo response in functional dyspepsia. Alimentary Pharmacology \& Therapeutics. 2006; 23:923-936.

Thomas KB. The placebo in general practice. The Lancet. 1994; 344: 166-167.

Thompson WG. The placebo effect and health. Combining science \& compassionate care. Ed. Prometheus Books; 2005.

Tsai SJ, Hong CJ, Yu YW, Chen TJ. Association study of catechol-O- 
metyltransferase gene and dopamine D4 receptor gene polymorphism and personality trais in healthy young Chinese females. Neuropsychobiology. $2004 ; 50$ : 153-156.

Unschuld PG, Ising M, Erhardt A, Lucae S, Kloiber S, Kohli M, Salyakina D, Welt T, Nikola K, Lieb R, Uhr M, Binder EB, Muller-Myhsok B, Holsboer F, Keck ME. Polymorphisms in the serotonin receptor gene HTR2A are associated with quantitative traits in panic disorder. American Journal of Genetics. 2007; 144B: 424429.

Van Tol HHM, Wu CM, Guan HC, Ohara K, Bunzow JR, Civelli O, Kennedy J, Seeman P, Niznik HB, Jovanovic V. Multiple dopamine D4 receptor variants in the human population. Nature. 1992; 358:149-152.

VanDenBrink AM, Vergouwe MN, Ophoff RA, Saxena PR, Ferrari M.D, Frants RR. 5HT1B receptor polymorphism and clinical response to sumatriptan. Headache. 1998; 38: 288-291.

Versiani M. A necessidade do grupo-controle com placebo em pesquisas sobre a eficácia de tratamentos psiquiátricos. Bioética. 2000; 8:(1): 29-42.

Vormfelde SV, Hoell I, Tzvetkov M, Jamrozinski K, Sehrt D, Brockmoller J, Leibing, E. Anxiety-and novelty seeking-related personality traits and serotonin transporter gene polymorphism. Journal of Psychiatric Research: in press.

Voudoris NJ, Peck CL, Coleman C. Conditioned placebo response. Journal of Personality and Social Psychology. 1985; 1:47-53.

Welge JA, Keck PE. Moderators of placebo response to antipsychotiv treatment in patients with schizophrenia: a meta regression. Psychopharmacology. 2003; 166:110.

World Medical Organization. Declaration of Helsinki. British Medical Journal; 1996; 313:1448-1449.

Yang $\mathrm{H}$, Cusin $\mathrm{C}$, Fava $\mathrm{M}$. Is there a placebo problem in antidepressant trials? Current Topics in Medicinal Chemistry. 2005; 5:1077-86. 